\title{
Necroptosis and Apoptosis Contribute to Cisplatin and Aminoglycoside Ototoxicity
}

\author{
Douglas Ruhl, ${ }^{1,2 *}$ Ting-Ting Du, ${ }^{1 \star}$ Elizabeth L. Wagner, ${ }^{1}$-Jeong Hwan Choi, ${ }^{1,3}$ Sihan Li, ${ }^{1}$ Robert Reed, ${ }^{1,2}$ Kitae Kim, ${ }^{1}$ \\ Michael Freeman, ${ }^{1}$ George Hashisaki, ${ }^{2}$ John R. Lukens, ${ }^{1}$ and Jung-Bum Shin ${ }^{1}$ \\ Departments of ${ }^{1}$ Neuroscience, ${ }^{2}$ Otolaryngology — Head and Neck Surgery, University of Virginia, Charlottesville, Virginia 22908, and ${ }^{3}$ Department of \\ Otolaryngology—Head and Neck Surgery, Inje University Sanggye Paik Hospital, Seoul 01757, Republic of Korea
}

Ototoxic side effects of cisplatin and aminoglycosides have been extensively studied, but no therapy is available to date. Sensory hair cells, upon exposure to cisplatin or aminoglycosides, undergo apoptotic and necrotic cell death. Blocking these cell death pathways has therapeutic potential in theory, but incomplete protection and lack of therapeutic targets in the case of necrosis, has hampered the development of clinically applicable drugs. Over the past decade, a novel form of necrosis, termed necroptosis, was established as an alternative cell death pathway. Necroptosis is distinguished from passive necrotic cell death, in that it follows a cellular program, involving the receptor-interacting protein kinase (RIPK) 1 and RIPK3. In this study, we used pharmacological and genetic interventions in the mouse to test the relative contributions of necroptosis and caspase-8-mediated apoptosis toward cisplatin and aminoglycoside ototoxicity. We find that ex vivo, only apoptosis contributes to cisplatin and aminoglycoside ototoxicity, while in vivo, necroptosis as well as apoptosis are involved in both sexes. Inhibition of necroptosis and apoptosis using pharmacological compounds is thus a viable strategy to ameliorate aminoglycoside and cisplatin ototoxicity.

Key words: aminoglycoside; apoptosis; cisplatin; hair cell; hearing; necroptosis

Significance Statement

The clinical application of cisplatin and aminoglycosides is limited due to ototoxic side effects. Here, using pharmaceutical and genetic intervention, we present evidence that two types of programmed cell death, apoptosis and necroptosis, contribute to aminoglycoside and cisplatin ototoxicity. Key molecular factors mediating necroptosis are well characterized and druggable, presenting new avenues for pharmaceutical intervention.

\section{Introduction}

The clinical application of the chemotherapeutic agent cisplatin, which is used in the treatment of various types of solid tumors (Einhorn, 2002; Burdett et al., 2015), is dose limited due to nephrotoxicity and ototoxicity (Karasawa and Steyger, 2015). Cisplatin results in the death of sensory hair cells, but the underlying mechanisms are still poorly understood (Sheth et al., 2017). Evidence suggests that cisplatin exerts its cytotoxic effect in hair cells through binding to cellular DNA, causing transcriptional inhibi-

\footnotetext{
Received May 30, 2018; revised Jan. 23, 2019; accepted Jan. 30, 2019.

Author contributions: D.R., J.R.L., and J.-B.S. designed research; D.R., T.-T.D., E.L.W., J.H.C., R.R., K.K., M.F., and J.-B.S. performed research; G.H., J.R.L., and J.-B.S. contributed unpublished reagents/analytic tools; D.R., T.-T.D., S.L., and J.-B.S. analyzed data; D.R. and J.-B.S. wrote the paper.

This study was supported by National Institutes of Health Grant R01-DC-014254. We thank the Virginia Lion's Hearing Foundation for financial support.

*D.R. and T.-T.D contributed equally to this work.

The authors declare no competing financial interests.

Correspondence should be addressed to Jung-Bum Shin at js2ee@virginia.edu.

https://doi.org/10.1523/JNEUROSCI.1384-18.2019

Copyright $\odot 2019$ the authors
}

tion and cell cycle arrest (St Germain et al., 2010), generation of reactive oxygen species, followed by mitochondrial damage and activation of apoptosis (Clerici et al., 1996; Kopke et al., 1997), involving the activation of mitogen-activated protein kinase pathways and caspases (St Germain et al., 2010). The clinical use of aminoglycoside antibiotics is also hampered by its ototoxic side effects. Aminoglycosides enter hair cells through the mechanotransduction channel, accumulate in hair cells (Richardson et al., 1997; Marcotti et al., 2005), cause oxidative stress (Priuska and Schacht, 1995), and initiate cell death through both caspasedependent and caspase-independent mechanisms (Cunningham et al., 2004). Although certain pathways are specific for cisplatin or aminoglycoside ototoxicity, the two pathologies share remarkable commonalities in the stress response they elicit in sensory hair cells: for example, both elicit oxidative stress (Lautermann et al., 1995; Clerici et al., 1996; Hirose et al., 1997; Kopke et al., 1997; Dehne et al., 2000), and activate p53 (Zhang et al., 2003; Coffin et al., 2013; Benkafadar et al., 2017) and the JNK pathway (Wang et al., 2004; Schacht et al., 2012; Francis et al., 2013). In addition, our laboratory previously demonstrated that both aminoglycoside- and 
cisplatin-induced ototoxicity is correlated with inhibition of cytosolic protein synthesis (Francis et al., 2013; Nicholas et al., 2017). Despite scores of compounds reported to protect against cisplatin- and aminoglycoside-induced ototoxicity, it is a concerning reality that none of the described compounds have entered clinical trials yet.

The stubborn intractability of cisplatin and aminoglycoside ototoxicity is likely caused by the fact that a multitude of stress pathways contribute to the pathology. Instead of attempting to block all upstream pathways involved, strategies to interfere with the final execution of cell death, by blocking programmed forms of cell death, could be a more tractable strategy to prevent ototoxicity. Caspase-mediated apoptosis is the most cited cell death pathway associated with ototoxicity, mainly affecting hair cells, stria vascularis and spiral ligament, and spiral ganglion cells (Alam et al., 2000; Liang et al., 2005). Indeed, pan-caspase inhibitors such as zVAD-FMK effectively prevent ototoxin-mediated hair cell loss in explant studies (Forge and Li, 2000; Cheng et al., 2003). In contrast to the ex vivo studies, the mode of cell death in vivo is thought to involve both apoptotic and necrotic cell death (Forge and Li, 2000; Matsui et al., 2003; Okuda et al., 2005; Jiang et al., 2006). Necrosis in its classic form lacks any specific molecular mediators, hence it is intractable for molecule-specific inhibition. Studies in the past 15 years, however, have uncovered an alternative programmed form of necrotic cell death termed necroptosis that is accessible for pharmacological intervention using a class of small-molecule inhibitors called necrostatins (Degterev et al., 2005; Linkermann and Green, 2014; Weinlich et al., 2017). Together with various mouse models that enabled lossof-function studies for mediators essential for necroptosis, including receptor-interacting protein kinase (RIPK) 1 and RIPK3 (Weinlich et al., 2017), this has allowed molecular dissection of the necroptosis pathways.

Here, we investigated the involvement of caspase-8-mediated apoptosis and RIPK1/3-mediated necroptosis in kanamycin and cisplatin ototoxicity. Using mice with null mutations in Ripk3 and/or Caspase-8 (Salmena et al., 2003; Newton et al., 2004), and pharmacological inhibition of necroptosis and apoptosis, we show that ex vivo, kanamycin and cisplatin ototoxicity is mediated solely by caspase-mediated apoptosis. In mature mice in vivo, however, both RIPK-mediated necroptosis and caspase-8mediated apoptosis contributed to cisplatin and aminoglycoside ototoxicity. Inhibition of necroptosis and apoptosis using pharmacological compounds is thus a clinically tractable strategy of preventing aminoglycoside and cisplatin ototoxicity.

\section{Materials and Methods}

Animal care and handling. The protocol for care and use of animals was approved by the University of Virginia Animal Care and Use Committee. The University of Virginia is accredited by the American Association for the Accreditation of Laboratory Animal Care. C57BL/6 (B16) mice used in this study were ordered from The Jackson Laboratory. Bl6 mice served as wild-type (WT) controls to match the strain background of the genetically modified mice also used in this study. Ripk3 KO mice were provided by Genentech. Ripk3 KO mice were bred with Caspase-8 (Casp8) heterozygous mice (Salmena et al., 2003; Newton et al., 2004) to produce Casp8/Ripk3 double KO (DOKO) mice. At the time of treatment, the mice ranged in age from 8 to 10 weeks. Mice of either sex were used (number of mice per sex is indicated in the figure legends). Neonatal mouse pups [postnatal day 3 (P3) to $\mathrm{P} 4$ ] were killed by rapid decapitation, and mature mice were killed by $\mathrm{CO}_{2}$ asphyxiation followed by cervical dislocation.

Organotypic explant cultures. Mouse cochleae and utricles were dissected in HBSS (Invitrogen) containing $25 \mathrm{~mm}$ HEPES, pH 7.5. The organ of Corti was separated from the spiral lamina and the spiral ligament using fine forceps and was attached to the bottom of sterile $35 \mathrm{~mm}$ BD Falcon Petri dishes (BD), with the hair bundle side facing up. The dissection medium was then replaced by two exchanges with culture medium (complete high-glucose DMEM containing 1\% FBS, supplemented with ampicillin and ciprofloxacin). Before experimental manipulation, explants were precultured for $24 \mathrm{~h}$ to allow acclimatization to the culture conditions (Francis et al., 2013). Cisplatin (injectable solution, 1 mg/ml; catalog \#NDC 0703-5748-11, Teva Pharmaceutical Industries) and kanamycin (Sigma-Aldrich) were dissolved in water. Stock solutions were prepared in DMSO for Necrostatin-1s (Nec-1s; $0.1 \mathrm{mg} / \mathrm{ml}$; RIP1 inhibitor II or 7-Cl-O-Nec-1, Millipore Sigma) and zVAD-FMK (10 mM; Selleckchem). All control cultures were supplemented with the equal amount of the vehicle (DMSO). The organs of Corti were cultured as a whole. The number of experiments $(n)$ for quantification of hair cell numbers, activated caspase-3-positive cells, and AHA ( $\alpha$-hydroxy acid) uptake indicate the number of organs.

Immunocytochemistry. Tissues were fixed for $25 \mathrm{~min}$ in $4 \%$ paraformaldehyde (PFA; catalog \#RT-15720, Electron Microscopy Science), washed three times for $5 \mathrm{~min}$ each in PBS, and incubated in blocking buffer (PBS containing 1\% bovine serum albumin, 3\% normal donkey serum, and $0.2 \%$ saponin) for $1 \mathrm{~h}$. Organs were then incubated with primary antibody overnight at room temperature in blocking buffer. Organs were washed three times for 5 min each with PBS and incubated with secondary antibodies (fluorophore-conjugated IgGs at 1:100; Invitrogen) and $0.25 \mu \mathrm{M}$ phalloidin-Alexa Fluor 488 (Invitrogen) in the blocking solution for 1-3 h. Finally, organs were washed five times in PBS and mounted in Vectashield (Vector Laboratories). Samples were imaged using Zeiss LSM810 Confocal Microscopes. The following antibodies were used in this study: mouse anti-MYO7A antibody (catalog \#MYO7A 138-1, Developmental Studies Hybridoma Bank; RRID: AB_2282417); rabbit anti-cleaved caspase-3 antibody (1:50; catalog \#9661, Cell Signaling Technology; RRID:AB_2341188); rabbit antiRIPK3 antibody (1:100; catalog \#95702, Cell Signaling Technology; RRID:AB_2721823); rabbit anti-RIPK3 antibody (1:100; catalog \#175631-AP, Proteintech Group; RRID:AB_2178659); and rabbit anti-RIPK3 antibody (1:100; catalog \#PRS2283, Sigma-Aldrich; RRID:AB_1856303; Zheng et al., 2014).

Hair cell counts from organ of Corti explant experiments. Hair cells were counted based on MYO7A immunoreactivity over a length of $100 \mu \mathrm{m}$ of the mid-basal turn of the cochlea, $\sim 4 \mathrm{~mm}$ from the apex (approximately corresponding to the $32 \mathrm{kHz}$ region). Cleaved caspase- 3 immunoreactivity was counted in the same area. At least six organs of Corti were analyzed for each experimental condition. Exact numbers of organs $(n)$ are indicated in the legends of the figures.

Hair cell counts from in vivo experiments. Mice were killed after the final auditory brainstem response (ABRs). Cochleae were dissected, openings were created at the base and apex of the cochlea and fixed in 4\% PFA for $24 \mathrm{~h}$. After decalcification for $7 \mathrm{~d}$ in EDTA solution, all turns of the cochlear sensory epithelium were dissected. Hair cell counting was performed for the organ of Corti using MYO7A immunoreactivity as a marker of hair cell presence. After confocal microscopy, images were analyzed using ImageJ. Hair cells were counted from the apical turn (0.5-1 $\mathrm{mm}$ from apex tip, corresponding to the $6-8 \mathrm{kHz}$ region), mid turn (1.9-3.3 $\mathrm{mm}$ from the apex tip, corresponding to $12-24 \mathrm{kHz}$ region), and basal turn (4.7-5.5 $\mathrm{mm}$ from the apex tip, corresponding to $48-64 \mathrm{kHz}$ region) of the cochlea. Hair cell numbers were converted and plotted as "percentage of control," by normalizing to the hair cell numbers in the corresponding area in vehicle-treated control mice. Organs of Corti from at least five mice were analyzed for each experimental condition. Exact numbers of organs $(n)$ are indicated in the legends.

Experimental design and statistical analysis. Sample sizes were calculated using a power analysis, based on variances of ABR threshold and hair cell counts observed historically in the Shin laboratory. Control groups consisted of mice of the same Bl6 background. Mice of either sex were used. For statistical analysis, GraphPad Prism (GraphPad) was used. Unless otherwise indicated, a two-way ANOVA was used to determine statistically significant differences between the means of the experimental groups. For multiple comparisons, a Dunnett's or Tukey's post 
hoc analysis was performed. $p$ Values $<0.05$ were considered statistically significant. All $n$ values in statistical analyses refer to number animals (for in vivo experiments) and organs of Corti (for ex vivo experiments). All error bars indicate the SD. Detailed results of the statistical tests are documented in Tables 1-1-7-1, available at https:/doi.org/10.1523/JNEUROSCI.138418.2019.t1-1, https://doi.org/10.1523/JNEUROSCI.1384-18.2019.t2-1, https://doi.org/10.1523/JNEUROSCI.1384-18.2019.t3-1, https://doi.org/ 10.1523/JNEUROSCI.1384-18.2019.t4-1, https://doi.org/10.1523/JNEUROSCI.1384-18.2019.t5-1, https://doi.org/10.1523/JNEUROSCI.138418.2019.t6-1, https://doi.org/10.1523/JNEUROSCI.1384-18.2019.t7-1.

Mouse model for cisplatin-mediated hearing loss. To elicit cisplatininduced hearing loss in the mouse, we followed a protocol established by Li et al. (2011). Mice were injected with $200 \mathrm{mg} / \mathrm{kg}$ body weight loop diuretic furosemide. One hour later, cisplatin was injected intraperitoneally at a concentration of $1 \mathrm{mg} / \mathrm{kg}$ body weight, in a total of $1 \mathrm{ml}$ of saline. This was repeated daily for a total of $3 \mathrm{~d}$. Control mice were injected with vehicle (saline or DMSO/saline mix) only. In groups treated with Nec-1s, the drug was injected intraperitoneally $1 \mathrm{~h}$ before treatment with cisplatin. Our standard dose of $3 \mathrm{mg} / \mathrm{kg} \mathrm{Nec-1s}$ was chosen from a priori protocols with dosing schedules ranging from 1.2 to $5 \mathrm{mg} / \mathrm{kg}$ (Tristão et al., 2016; Wang et al., 2017).

In the loop diuretics-free cisplatin ototoxicity model (Roy et al., 2013), mice were prehydrated with $2-3 \mathrm{ml}$ of subcutaneous saline $24 \mathrm{~h}$ before the first cisplatin injection. Mice were injected with $3 \mathrm{mg} / \mathrm{kg}$ cisplatin, i.p., once daily for $4 \mathrm{~d}$ followed by $10 \mathrm{~d}$ of recovery. This regimen was repeated three times. After the final cisplatin injection, mice underwent an additional $5 \mathrm{~d}$ of recovery, followed by post-test ABR assessment. Enhanced husbandry for cisplatin-treated mice was provided according to the study by Roy et al. (2013).

Mouse model for kanamycin-mediated hearing loss. To elicit kanamycininduced hearing loss in the mouse, we followed a furosemide/kanamycin combination protocol (Taylor et al., 2008). Mice were injected once with $600 \mathrm{mg} / \mathrm{kg}$ kanamycin, i.p., followed $1 \mathrm{~h}$ later by a dose of $400 \mathrm{mg} / \mathrm{kg}$ furosemide, i.p. In treatment groups treated with Nec-1s (3 or $0.3 \mathrm{mg} /$ $\mathrm{kg}$ ), the drug was injected in an intraperitoneal fashion $1 \mathrm{~h}$ before treatment with kanamycin.

In the loop diuretics-free kanamycin ototoxicity model (Roy et al., 2013), in brief, mice received twice daily intraperitoneal injections of kanamycin $(750 \mathrm{mg} / \mathrm{kg}), 8 \mathrm{~h}$ apart, for $17 \mathrm{~d}$. Mice recovered for $21 \mathrm{~d}$ before the post-treatment ABR.

Auditory brainstem response testing. ABR testing was performed in each mouse before the initiation of drug treatment, $48 \mathrm{~h}$ post-kanamycin treatment, $10 \mathrm{~d}$ post-cisplatin treatment, and 2 weeks following initial post-treatment ABR. Anesthesia with a single intraperitoneal injection of ketamine at $100 \mathrm{mg} / \mathrm{kg}$ was performed before testing. The mouse was then placed on a Deltaphase Isothermal Warming Pad (Braintree Scientific), and subdermal needle electrodes (FE-7, Grass Technologies) were inserted as follows: (1) reference electrode was inserted into the mastoid area of the right ear; (2) the active electrode was inserted at the vertex of the scalp; (3) the ground electrode was inserted into the left gluteus. All ABR testing took place in a sound-attenuating box (Med Associates) with digital stimuli (Intelligent Hearing Systems) and were delivered to the right ear by a high-frequency speaker (model AS-TH400A) through a plastic tube placed in the ear canal. Stimulus was delivered at 32, 22.4, $16,11.3$, and $8 \mathrm{kHz}$ in 1024 sweeps. After testing revealed observable response waveforms, the stimulus was decreased by $10 \mathrm{~dB}$ until responses were no longer observed. Repeat testing at $5 \mathrm{~dB}$ increments above and below the sound level at which waveforms disappeared confirmed the threshold. Waves II and III served as landmarks for threshold determination.

\section{Results}

Pharmacological inhibition of RIPK1 and downstream necroptosis does not protect from kanamycin- or cisplatin-induced hair cell death ex vivo

The relative contribution of apoptosis and necrosis to druginduced hair cell death was reported to differ between ex vivo and in vivo experimental contexts (Forge and Schacht, 2000; Jiang et al., 2006; Rybak et al., 2006). For a comprehensive appreciation of the role of necroptosis and apoptosis in aminoglycoside and cisplatin ototoxicity, we therefore performed both ex vivo and in vivo experiments. Nec-1s is a selective inhibitor of RIPK1, which, in conjunction with RIPK3, is the principal mediators of necroptosis (Weinlich et al., 2017). We first conducted a dose-response study of the effect of $\mathrm{Nec}-1$ s on kanamycin and cisplatin toxicity in early postnatal organ of Corti explant cultures (ex vivo). Organ of Corti explants were precultured overnight in growth medium, and cultured for another $24 \mathrm{~h}$ with $0,0.2,1,3$, and $10 \mu \mathrm{M} \mathrm{Nec}-1 \mathrm{~s}$, in the absence or presence of $100 \mu \mathrm{M}$ cisplatin or $1000 \mu \mathrm{M}$ kanamycin. After culture, organs were fixed and processed for immunohistochemistry to visualize F-actin (phalloidin), MYO7A, and cleaved Caspase-3 (Casp-3) immunoreactivity. Hair cell numbers and the frequency of cleaved Casp-3-positive cells of Nec-1s treated cultures were comparable to those in vehicle-treated controls, suggesting that the inhibition of RIPK1-mediated necroptosis had no effect on hair cells (Fig. 1A) and failed to provide any protection from cisplatin- and kanamycin-induced hair cell death ex vivo (Fig. $1 B, C$ ). A notable difference between kanamycin and cisplatin was that the former caused apoptosis only in hair cells, while the latter also affected supporting cells, as evident in the abundance of Casp-3-positive, but MYO7A-negative, cells in the cisplatin-treated group (Fig. $1 D$, dotted white line outlining exemplary group of cells). This is consistent with previous findings that reported a broader cytotoxic effect of cisplatin in ex vivo experiments (Nicholas et al., 2017). We next examined the combined effect of pan-caspase inhibition (by zVAD-FMK) and RIPK1 inhibition (by Nec-1s). The ototoxins (cisplatin or kanamycin) and the inhibitors (zVAD-FMK and Nec-1s, individually or in combination) were added simultaneously to the explant cultures. In contrast to Nec-1s, the pan-caspase inhibitor zVADFMK at $100 \mu \mathrm{M}$ concentration was highly effective in preventing both Caspase-3 cleavage and hair cell death in explants exposed to kanamycin or cisplatin (Fig. $1 D-F$ ). The completeness of zVADFMK-mediated protection against cisplatin- or kanamycin-induced hair cell death, and the lack of protection by Nec-1s, suggested that ex vivo, the predominant form of cisplatin- and kanamycin-induced hair cell death is mediated by caspase-dependent apoptosis, without contribution from necroptosis.

\section{Pharmacological blockade of RIPK1 protects against kanamycin-induced hair cell death in vivo}

Next, we tested the otoprotective potential of Nec-1s in vivo. Previous studies had shown that, in contrast to ex vivo cultures, both apoptosis and necrosis contribute to ototoxicity in vivo (Jiang et al., 2006). We thus hypothesized that in vivo, necroptosis might contribute significantly to kanamycin- and cisplatinmediated ototoxicity. We first tested whether Nec-1s treatment protects against kanamycin ototoxicity in the mouse. ABRs were measured $1 \mathrm{~d}$ before the administration of drugs (pre-exposure ABRs). Nec-1s (3 or $0.3 \mathrm{mg} / \mathrm{kg}$ body weight) was administered intraperitoneally, followed $1 \mathrm{~h}$ later with a mix of kanamycin and loop diuretics (Fig. 2A). Post-exposure ABRs were measured $2 \mathrm{~d}$ after drug administration, after which mice were killed and processed for hair cell counts. In contrast to ex vivo, RIPK inhibition by $\mathrm{Nec}-1 \mathrm{~s}$ provided significant protection from kanamycininduced hearing loss in vivo: Control mice treated with a kanamycin/furosemide combination developed hearing loss across all frequencies, with $\mathrm{ABR}$ thresholds ranging between $\sim 70$ and 80 $\mathrm{dB} 2 \mathrm{~d}$ after the kanamycin injection (Fig. $2 B, E$ ). The broad range of affected frequencies is in agreement with previous reports us- 
A

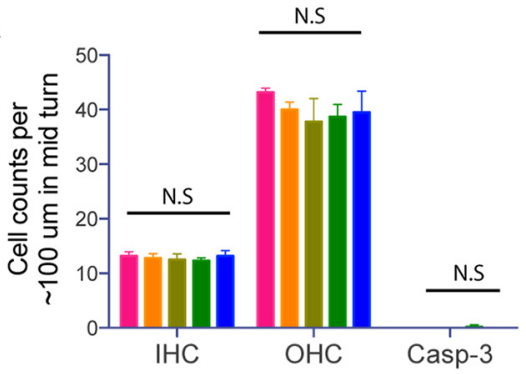

vehicle

Nec-1s (0.2 uM)

Nec-1s (1 uM)

Nec-1s (3 uM)

Nec-1s (10 uM)
B

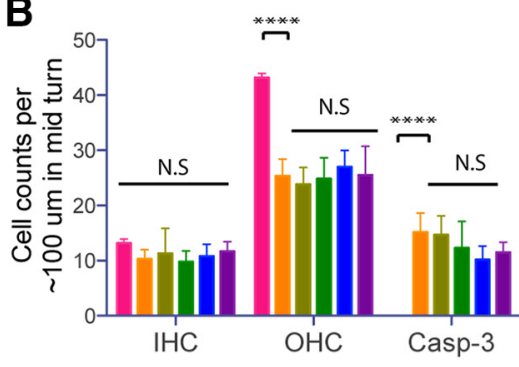

vehicle

Kan $1000+$ Nec-1s (0 uM)

Kan $1000+$ Nec-1s (0.2 uM)

Kan $1000+$ Nec-1s (1 uM)

Kan $1000+$ Nec-1s (3 uM)

Kan $1000+$ Nec-1s (10 uM)
C

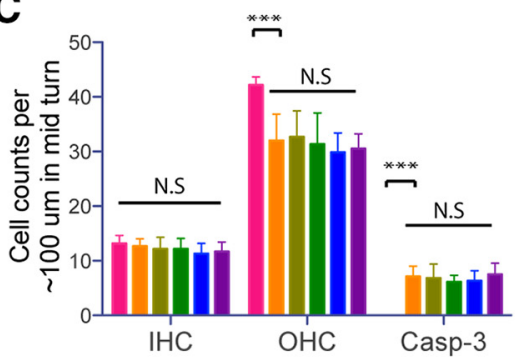

vehicle

Cis $100+$ Nec-1s (0 uM)

Cis $100+$ Nec-1s $(0.2 \mathrm{uM})$

Cis $100+\mathrm{Nec}-1 \mathrm{~s}$ (1 uM)

Cis $100+$ Nec-1s (3 uM)

Cis $100+$ Nec-1s (10 uM)

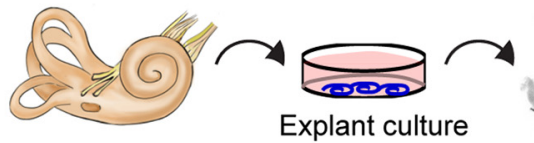

D
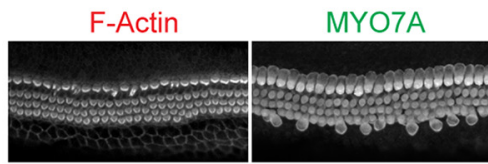

is
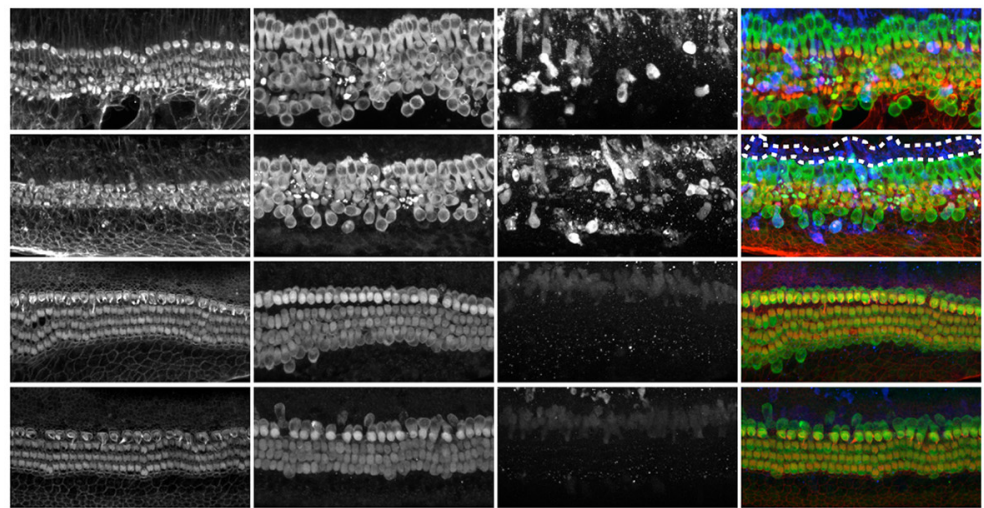

$+\mathrm{Nec} 1 \mathrm{~s}$
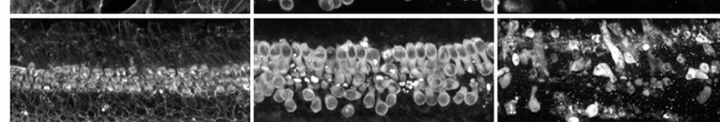

Cis

$+\mathrm{zVad}$

Cis

\section{+Nec1s}

$+\mathrm{zVad}$
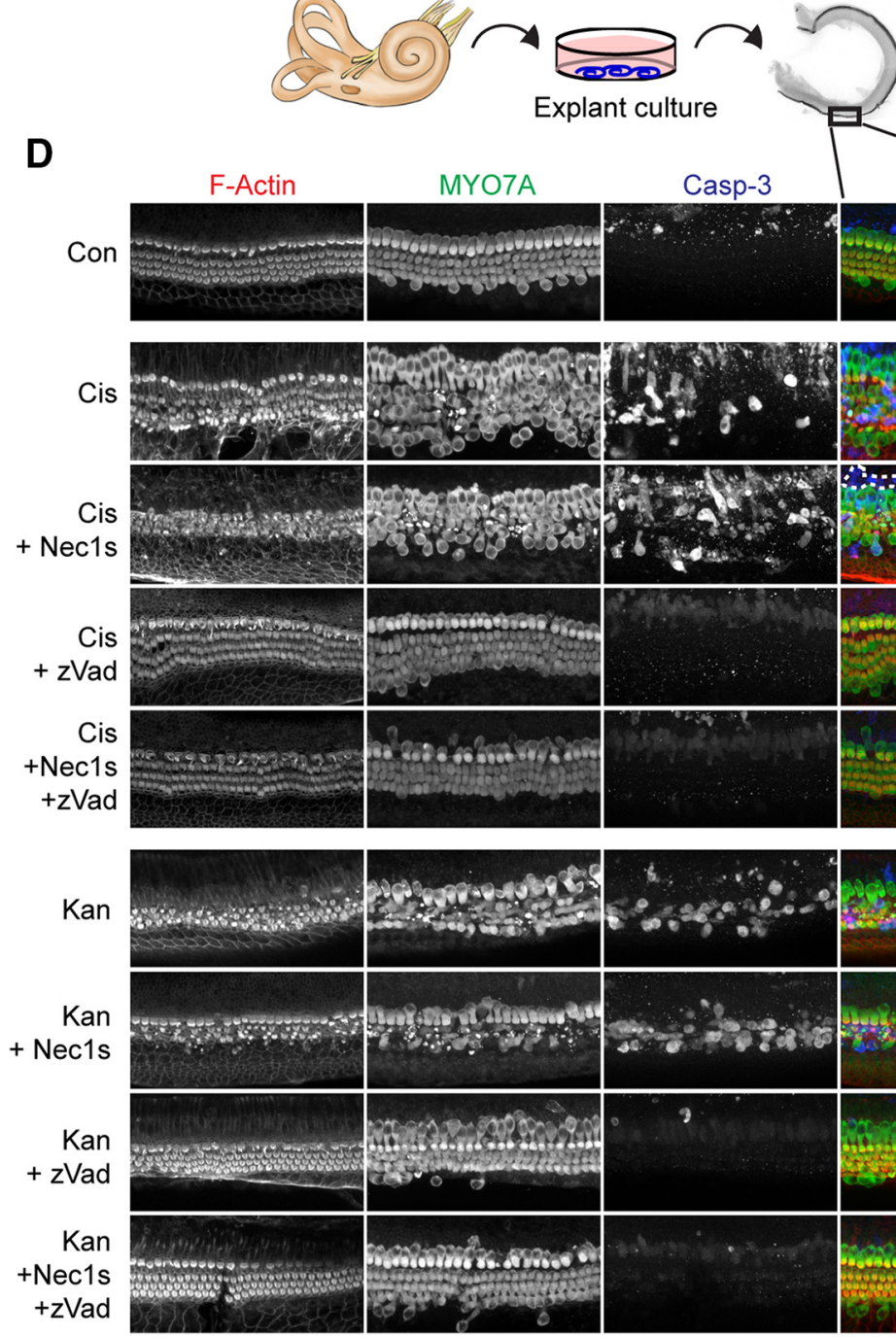

ㄹ

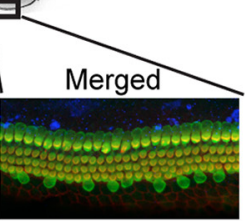

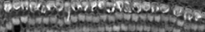
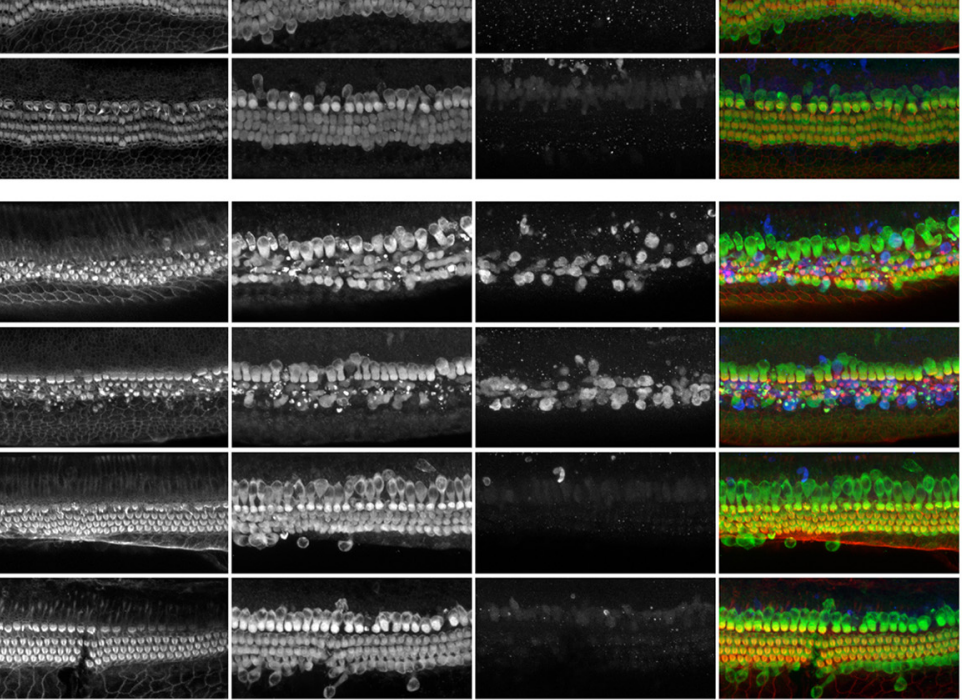

E

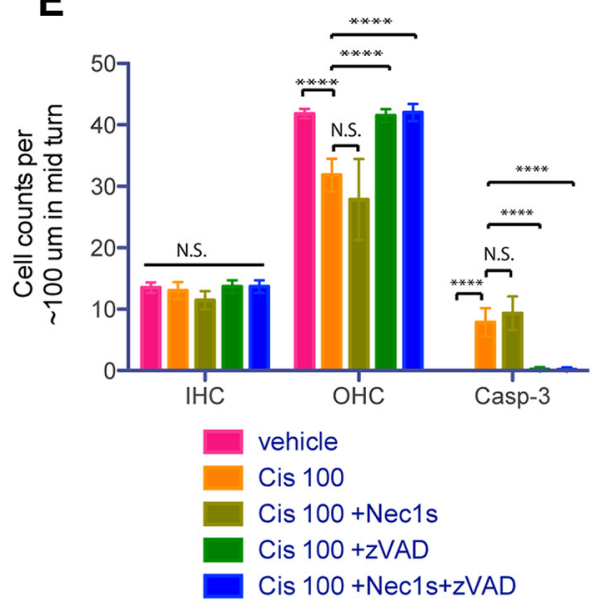

F

$F$

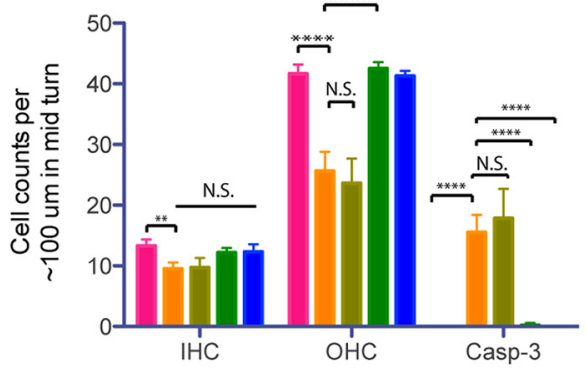

vehicle

Kan 1000

Kan $1000+$ Nec1s

- Kan $1000+z V A D$

Kan 1000+Nec1s+zVAD

Figure 1. Necrostatin-1s does not protect from kanamycin- or cisplatin-induced hair cell death in early postnatal organ of Corti explant cultures. $\boldsymbol{A}-\boldsymbol{C}$, Dose-response of Nec-1s alone $(\boldsymbol{A})$, Nec-1s

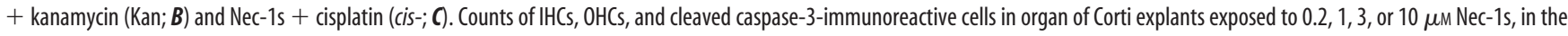
absence or presence of $1000 \mu \mathrm{m}$ kanamycin or $100 \mu \mathrm{m}$ cisplatin. $\boldsymbol{D}$, Representative images of $100-\mu \mathrm{m}$-long sections in the mid-basal region of cochlear explants under various experimental conditions: control (con), cis- (cisplatin treated), cis- + Nec-1s (cisplatin and Nec-1s treated), cis- + zVAD (cisplatin and zVAD-FMK treated), cis- + Nec-1s + zVAD (cisplatin, Nec-1s, and zVAD-FMK treated), Kan (kanamycin treated), Kan + Nec-1s (kanamycin and Nec-1s treated), Kan + zVAD (kanamycin and zVAD-FMK treated), and Kan + Nec-1s + zVAD (kanamycin, Nec-1s, and zVAD-FMK treated). MY07A (green in the merged images) served as a hair cell-specific marker, and activated Casp-3 (blue) served as a marker for cells undergoing apoptosis. The dotted area in the cis- + Nec1s row indicates supporting cells (MY07A negative, Casp-3 positive) undergoing apoptosis. IHC, OHC, and caspase-3-positive cells are quantified in $\boldsymbol{E}$ and $\boldsymbol{F}$. Statistical significance: ${ }^{* * * *} p<0.00001$, ${ }^{* * *} p<0.0001,{ }^{* *} p<0.001,{ }^{*} p<0.05$. Number of organs $(n)$ per group, 6 . Explant cultures were established from mice of either sex. For statistical analysis, two-way ANOVA was performed, followed by a Dunnett's post-test [multiple comparisons to one control condition: control for $A$, vehicle; control for $B$ and F, Kan $1000+N e c-1 s(0 \mu \mathrm{M})$; control for Cand E, cis-100 + Nec-1s $(0 \mu \mathrm{M})$ ]. See Table 1-1 available at https://doi.org/10.1523/JNEUROSCI.1384-18.2019.t1-1. 
A

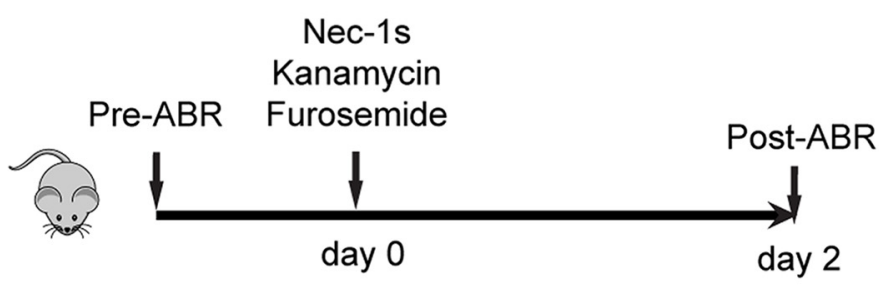

B

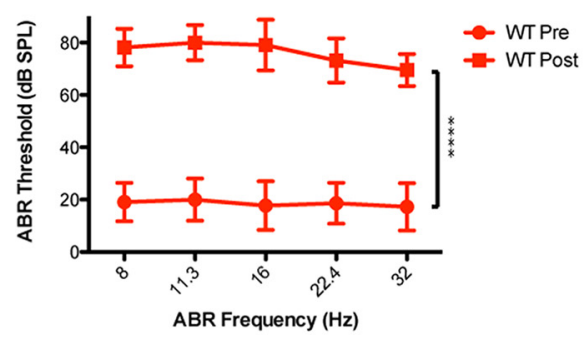

C

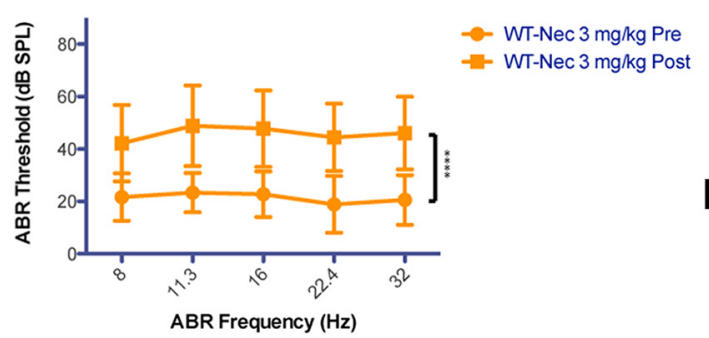

D

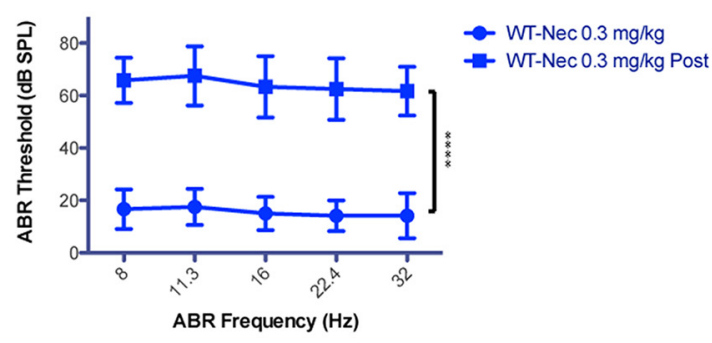

E

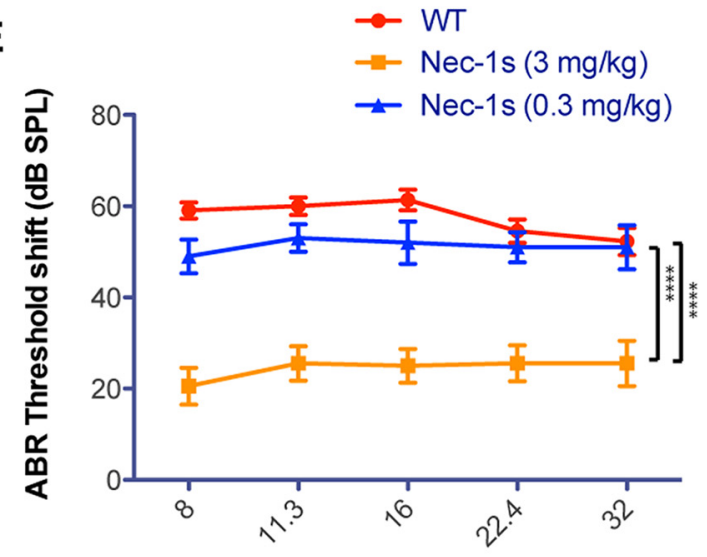

ABR Frequency $(\mathrm{Hz})$

$\mathbf{F}$
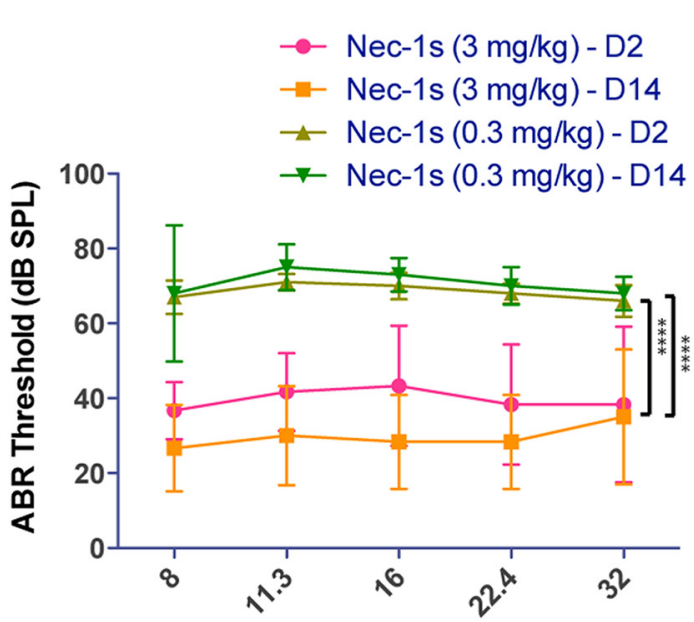

ABR Frequency

Figure 2. Nec-1s protects from kanamycin-induced hair cell death in vivo. $A$, Schematic illustration of the kanamycin/furosemide combination ototoxicity paradigm. $A-D, A B R$ thresholds measured $1 \mathrm{~d}$ prior (pre) and $2 \mathrm{~d}$ after (post) the application of kanamycin/furosemide (according to $\boldsymbol{A}$ ) in WT mice injected with vehicle $(\boldsymbol{B}), 3 \mathrm{mg} / \mathrm{kg}$ body weight Nec- $1 \mathrm{~s}(\boldsymbol{C})$, and $0.3 \mathrm{mg} / \mathrm{kg}$ body weight Nec-1s (D). $\boldsymbol{E}$, The shifts (difference between pre- and postexposure ABRs) are summarized for all three experimental treatments. The colors correspond to the respective colors in the individual plots. F, Follow-up study of ABR thresholds $14 \mathrm{~d}$ after exposure. Error bars indicate the SD. Statistical significance: ${ }^{* * * *} p<0.00001,{ }^{* * *} p<0.0001$. Number of animals $(n)$ per group: WT vehicle-treated ( $n=11,7$ females, 4 males), WT Nec- $1 \mathrm{~s}$ ( $3 \mathrm{mg} / \mathrm{kg})$ treated ( $n=9,5$ females, 4 males), and WT Nec- $1 \mathrm{~s}(0.3 \mathrm{mg} / \mathrm{kg})$ treated $(n=5,3$ females, 2 males). See Table $2-1$ available at https://doi.org/10.1523/JNEUROSCl.1384-18.2019.t2-1.

ing the combined kanamycin/loop diuretic hair cell damage protocol (Hirose and Sato, 2011). Figure 2B-D indicates absolute ABR thresholds, while the summary plot (Fig. 2E) shows the relative $A B R$ threshold difference (shift) between pre-ABRs and post-ABRs. In mice that were additionally treated with $3 \mathrm{mg} / \mathrm{kg}$ Nec-1s, the thresholds increased only to $\sim 40-50 \mathrm{~dB}$ across tested frequencies, representing an improvement of threshold shift by an average of $\sim 30 \mathrm{~dB}$ in this group (Fig. $2 C, E$ ). When Nec-1s was administered at a 10 -fold diluted concentration, the protective effect was lost, demonstrating a dose-dependent protection of Nec-1s in vivo (Fig. $2 D, E$ ). To test whether the protective effect of $\mathrm{Nec}$-1s was maintained after withdrawal of the drug, we determined ABR thresholds $14 \mathrm{~d}$ after Nec-1s administration. The improvement in hearing threshold in the Nec-1s-treated group was maintained at day 14 (Fig. 2F), suggesting that the beneficial effect of $\mathrm{Nec}-1 \mathrm{~s}$ for hearing function persisted after its withdrawal. It should be noted that the ototoxin kanamycin was also absent during this time period. We conclude that, in vivo, necroptosis contributes significantly to kanamycin-induced hearing loss.

\section{Pharmacological blockade of RIPK1 protects against} cisplatin-induced hair cell death in vivo

We next tested whether $\mathrm{Nec}-1 \mathrm{~s}$ also alleviates cisplatin-induced ototoxicity in vivo. ABRs were tested $1 \mathrm{~d}$ before administration of drugs (pre-exposure ABRs). Nec-1s ( 3 or $0.3 \mathrm{mg} / \mathrm{kg}$ body weight) 
A
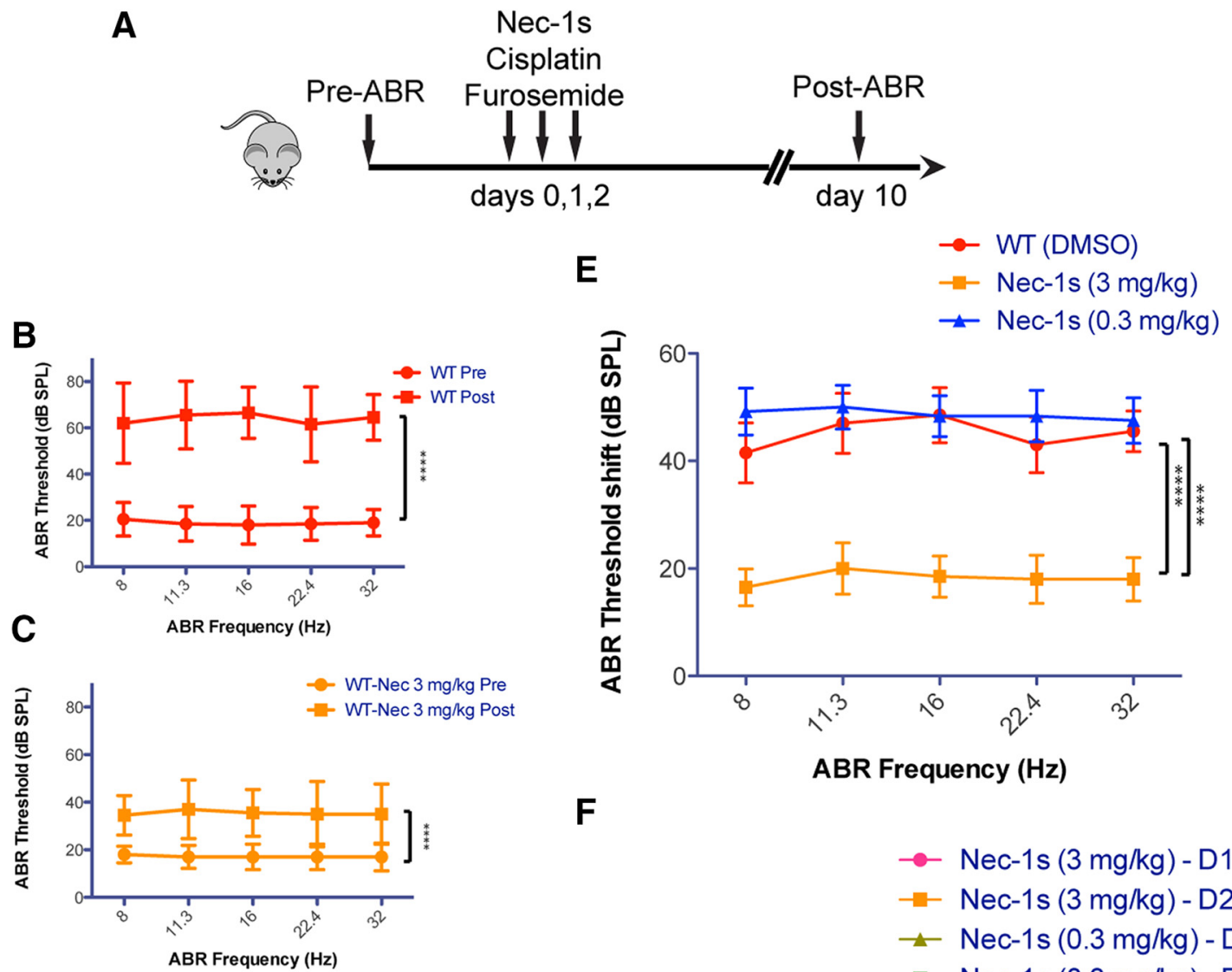

$\mathbf{F}$

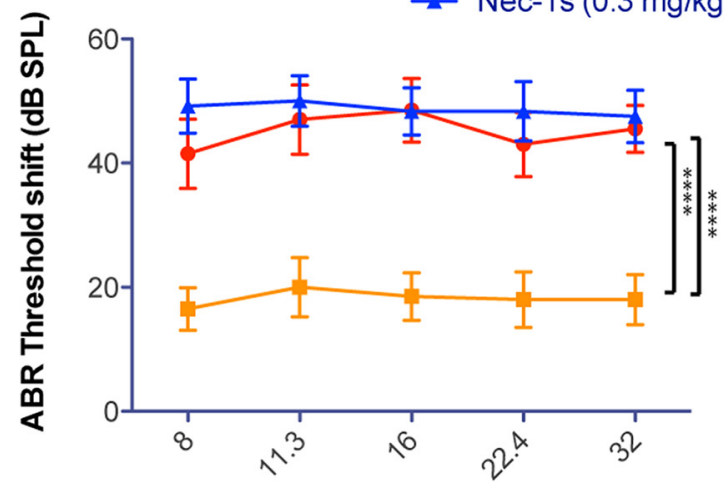

ABR Frequency $(\mathrm{Hz})$
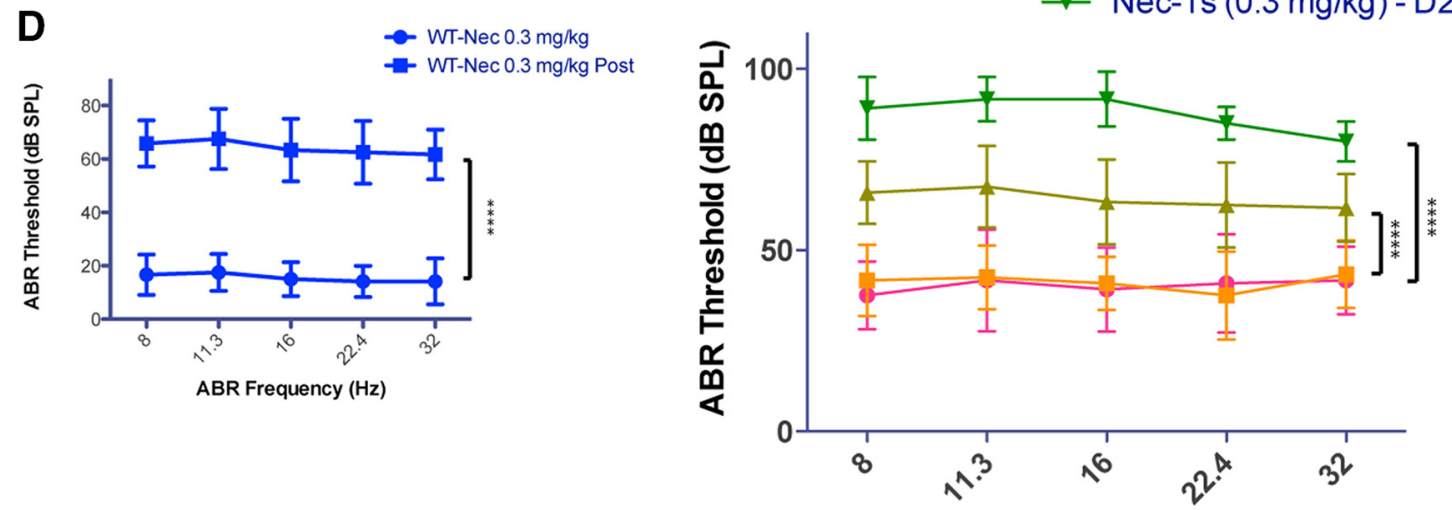

ABR Frequency

Figure 3. Nec-1s protects from cisplatin-induced hair cell death in vivo. $A$, Schematic illustration of the cisplatin/furosemide combination ototoxicity paradigm. $A-D, A B R$ thresholds measured $1 \mathrm{~d}$ prior and $10 \mathrm{~d}$ after the application of cisplatin/furosemide (according to $\boldsymbol{A}$ ) in WT mice injected with vehicle (B), $3 \mathrm{mg} / \mathrm{kg}$ body weight Nec-1s (C), and $0.3 \mathrm{mg} / \mathrm{kg}$ body weight Nec- $-1 \mathrm{~s}(\boldsymbol{D})$. $\boldsymbol{E}$, The shifts (difference between pre- and post-exposure ABRs) are summarized for all three experimental treatments. The colors correspond to the respective colors in the individual plots. $\boldsymbol{F}$, Follow-up study of ABR thresholds $24 \mathrm{~d}$ (D24) after exposure, compared with the initial post-ABRs $10 \mathrm{~d}$ (D10) after exposure. Error bars indicate the SD. Statistical significance: ${ }^{* * * *} p<0.00001,{ }^{* * *} p<$ 0.0001. Number of animals $(n)$ per group: WT vehicle treated $(n=10,7$ females, 3 males); WT Nec- $1 \mathrm{~s}(3 \mathrm{mg} / \mathrm{kg})$ treated $(n=10,5$ females, $5 \mathrm{males}) ;$ and WT Nec $-1 \mathrm{~s}(0.3 \mathrm{mg} / \mathrm{kg})$ treated $(n=6$, 4 females, 2 males). See Table 3-1 available at https://doi.org/10.1523/JNEUROSCI.1384-18.2019.t3-1.

was administered intraperitoneally, followed $1 \mathrm{~h}$ later by a mix of cisplatin with a loop diuretic (furosemide; Fig. $3 A$ ). This was repeated daily for $3 \mathrm{~d}$. Post-exposure ABRs were measured $10 \mathrm{~d}$ after the completion of drug administration, after which mice were killed and processed for hair cell counts. Similar to the results for kanamycin ototoxicity, the administration of 3 $\mathrm{mg} / \mathrm{kg} \mathrm{Nec-1s} \mathrm{provided} \mathrm{significant} \mathrm{protection} \mathrm{from} \mathrm{ototoxic}$ hearing loss. ABR thresholds improved an average of $\sim 30 \mathrm{~dB}$ across all tested frequencies in the Nec-1s-treated group (Fig. $3 B, C, E)$. When $\mathrm{Nec}-1 \mathrm{~s}$ was administered at a 10 -fold diluted concentration, the protective effect was again lost, and hearing thresholds reverted to values similar to WTs exposed to cisplatin (Fig. $3 D, E$ ). Figure $3 B-D$ indicates ABR thresholds, while the summary plot in Figure $3 E$ shows the ABR threshold shifts between pre-ABRs and post-ABRs. To test whether the protective effect of $\mathrm{Nec}-1 \mathrm{~s}$ was maintained after withdrawal of the drug, we performed a separate experiment in which ABR thresholds were determined $24 \mathrm{~d}$ (initial post-exposure ABRs at day 10) after Nec-1s administration. The hearing benefit in the Nec-1streated group was maintained up to $24 \mathrm{~d}$, while the hearing thresholds without Nec-1s treatment even worsened between day 10 and 
day 24 after cisplatin treatment (Fig. 3F), suggesting that the beneficial effect of Nec-1s for hearing function persisted after its withdrawal. Together, we conclude that the effect of Nec-1s mediated inhibition of necroptosis differs starkly between in vivo and ex vivo experiments, and that in vivo pharmacological inhibition of RIPK1mediated necroptosis alleviates both kanamycin- and cisplatininduced hearing loss.

\section{Casp8/Ripk3 DOKO mice have normal hearing}

Next, we used genetic mouse models to assess the relative contributions of RIPK 3 and Caspase- 8 in kanamycin and cisplatin ototoxicity in vivo. We decided to make use of mice that harbor single mutations in the Ripk3 gene or combined null mutations in the Ripk3 and Casp8 genes. RIPK3, which is recruited by RIPK1 to assemble the necrosome (He et al., 2009; Li et al., 2012) is an essential mediator of necroptosis. Caspase- 8 is an "initiator caspase" essential for death receptor-mediated (extrinsic) apoptosis (Chen and Wang, 2002; Boatright and Salvesen, 2003). Ripk3 KO (global KO) mice were previously shown to lack any phenotype at basal state (Newton et al., 2004), but were protected from various types of stress-related responses (Duprez et al., 2011; Ramachandran et al., 2013; Murakami et al., 2014). Casp8 KO mice exhibit embryonic lethality, but, fortuitously, the embryonic lethality of Casp 8 deletion is mediated by RIPK3, so that mice with a dual deletion of Casp 8 and Ripk3 are viable and healthy, with the exception of developing lymphadenopathy starting at $\sim 14-16$ weeks of age (Kaiser et al., 2011). The present experiments were performed with mice 8-10 weeks of age to avoid unforeseen interactions with the lymphadenopathy symptoms. To sum up our choice of mouse strains, we used Ripk3 KO mice to study the effect of genetic inhibition of RIPK-mediated necroptosis, and Casp8/Ripk3 DOKO mice to study the combined effect of genetically inhibiting both necroptosis and extrinsic apoptosis on kanamycin- and cisplatin-mediated ototoxicity.

Before exposing the mice to the ototoxicity protocols, we first ascertained that the Casp8/Ripk3 DOKO mice have normal hearing function. We performed a longitudinal hearing function study, testing ABRs at $8,11,14$, and 20 weeks of age in Casp8/ Ripk3 DOKO and WT controls and found no significant differences between the two groups (Fig. $4 A-D$ ). We also tested whether the lack of Caspase- 8 might affect the occurrence of apoptosis in the Kolliker's organ between P7 and P13, which is thought to contribute to the remodeling of the greater epithelial ridge during postnatal development (Hinojosa, 1977; Knipper et al., 1999; Kamiya et al., 2001). Counting cleaved Caspase-3positive cells in Kolliker's organ at P8 did not reveal any differences between Casp8/Ripk3 DOKO and WT controls (Fig. 4E,F). We conclude that cochlear development and hearing function is not affected in Casp8/Ripk3 DOKO mice.

\section{Genetic inhibition of RIPK3 and Caspase-8 alleviates kanamycin ototoxicity in vivo}

We next tested whether Ripk3 KO mice and Casp8/Ripk3 DOKO mice are protected from kanamycin ototoxicity in vivo. Mice were exposed to the same kanamycin ototoxicity protocol used for the Nec-1s inhibitor studies (Fig. 5A). When WT mice were exposed to kanamycin, the hearing thresholds increased by $\sim 50-60 \mathrm{~dB}$ compared to pre-exposure ABR thresholds, affecting all frequencies in a comparable manner (Fig. $5 B, E$ ). The Figure $5 B-D$ indicate absolute ABR thresholds, while the summary plot in Figure $5 E$ plots the ABR threshold difference (shift) between pre-ABRs and post-ABRs. Ripk3 $\mathrm{KO}$ mice presented with $\mathrm{ABR}$ thresholds that were significantly improved compared with WT mice, with thresholds shifting $2 \mathrm{~d}$ after kanamycin exposure by only $\sim 30 \mathrm{~dB}$ on average (Fig. 5C,E). Casp8/Ripk3 DOKO mice were the most protected, with ABR thresholds shifting by only $\sim 15-20 \mathrm{~dB}$ after kanamycin exposure (Fig. 5D,E).

The ototoxicity protocol used in this study so far used loop diuretics to increase penetration of ototoxins through the bloodlabyrinth barrier. This causes additional damage to the stria vascularis (Hirose and Sato, 2011), complicating interpretation of the experimental results. We therefore sought to confirm our findings using a kanamycin ototoxicity protocol that omits the use of loop diuretics (Hirose and Sato, 2011; Roy et al., 2013), involving daily injections of kanamycin for 2 weeks, followed by a $20 \mathrm{~d}$ recovery period (Fig. $5 F$ ). With this protocol, WT mice experienced a threshold shift of $\sim 20 \mathrm{~dB}$ at low frequencies $(8 \mathrm{kHz})$ to $\sim 40 \mathrm{~dB}$ at high frequencies $(32 \mathrm{kHz})$. In contrast, Casp8/Ripk3 DOKO mice were fully protected from kanamycininduced hearing loss (Fig. 5G,H), even surpassing the protection achieved with the furosemide-aided protocol.

\section{Genetic inhibition of RIPK3 and Caspase-8 alleviates cisplatin ototoxicity in vivo}

We next tested whether Ripk3 KO mice and Ripk3/Casp8 DOKO mice are protected from cisplatin ototoxicity in vivo. Mice were exposed to the cisplatin ototoxicity protocol used for the Nec-1s inhibitor studies (Fig. 6A). WT mice exposed to cisplatin presented with hearing thresholds of $\sim 60-70 \mathrm{~dB}$, which constitutes a shift of $\sim 40-50 \mathrm{~dB}$ compared with pre-exposure ABRs. All frequencies were affected in a comparable manner (Fig. $6 B, E$ ). Ripk3 KO mice presented with hearing thresholds of $\sim 40-50 \mathrm{~dB}$, which constitutes a shift of only 15-20 dB compared to preexposure ABRs, and thus were significantly improved compared with WT mice (Fig. 6C,E). Casp8/Ripk3 DOKO mice experienced the most pronounced protection, with ABR thresholds shifting by only $\sim 10 \mathrm{~dB}$ after cisplatin exposure (Fig. $6 D, E$ ).

We attempted to confirm the protection in the Casp8/Ripk3 DOKO mice using a cisplatin ototoxicity protocol that omits the use of loop diuretics (Roy et al., 2013). This $47 \mathrm{~d}$ regimen involves once-daily injections of cisplatin for $4 \mathrm{~d}$, followed by $10 \mathrm{~d}$ of recovery, and repeated three times. Unfortunately, this protocol, despite enhanced daily husbandry of animals, caused an $80 \%$ mortality rate in the Casp8/Ripk3 DOKO strain (data not shown). Since the WT mice survived this protocol, this is an interesting genotype-specific increase in mortality that warrants future investigations.

\section{The otoprotective effect of inhibiting RIPK3-mediated necroptosis and Caspase-8-mediated apoptosis correlates with improved hair cell survival}

If the improved hearing performance in mice treated with $\mathrm{Nec}-1 \mathrm{~s}$ or deficient for Ripk3 and/or Casp 8 is mediated by the inhibition of necroptotic and/or apoptotic cell death, it should be reflected in improved hair cell survival. We tested this by counting cochlear hair cells from all experimental groups. Hair cell counts were performed from the apical turn $(0.5-1 \mathrm{~mm}$ from apex tip, corresponding to the $6-8 \mathrm{kHz}$ region), mid turn $(1.9-3.3 \mathrm{~mm}$ from the apex tip, corresponding to the $12-24 \mathrm{kHz}$ region), and basal turn (4.7-5.5 $\mathrm{mm}$ from the apex tip, corresponding to the $48-64 \mathrm{kHz}$ region) of the cochlea. In WT mice exposed to kanamycin, inner hair cells (IHCs) in the apical and mid-regions were mostly unaffected, but basal inner hair cells were significantly reduced in numbers (IHC counts $\sim 80 \%$ lower compared with 
A

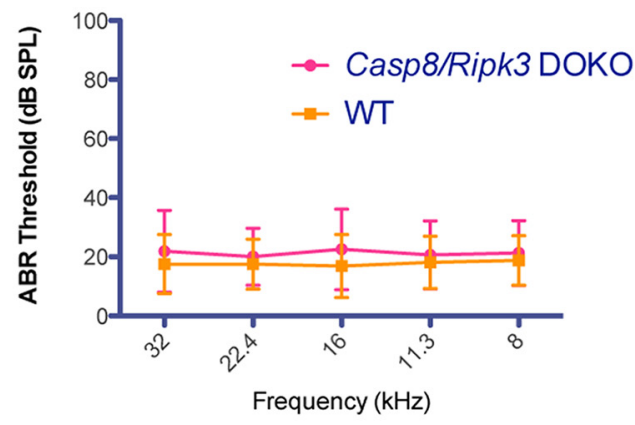

C

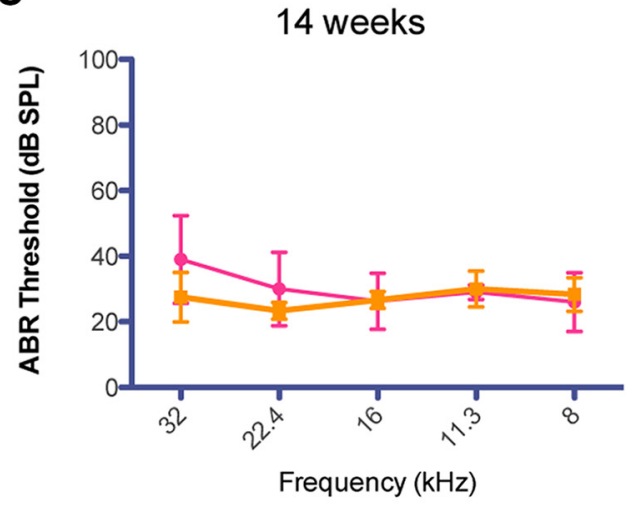

B

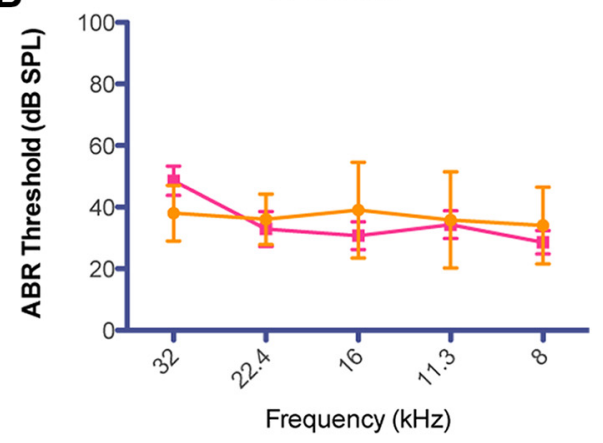

D

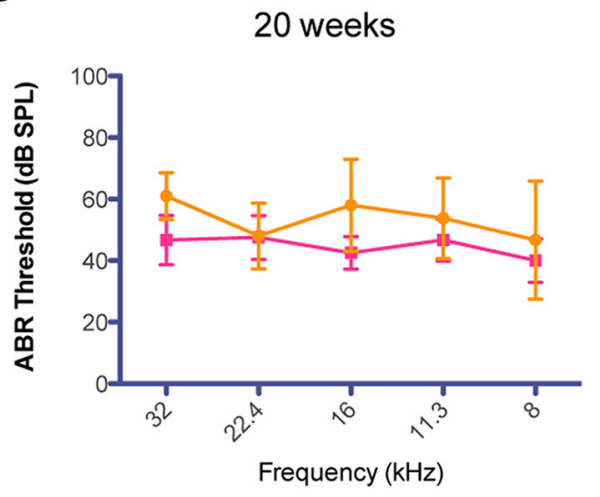

E

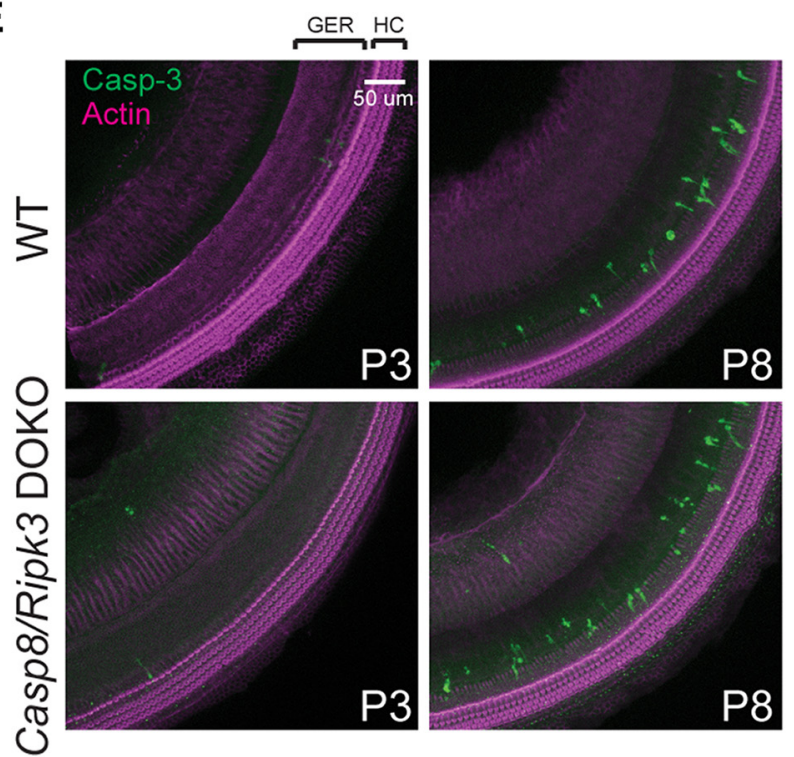

$\mathbf{F}$

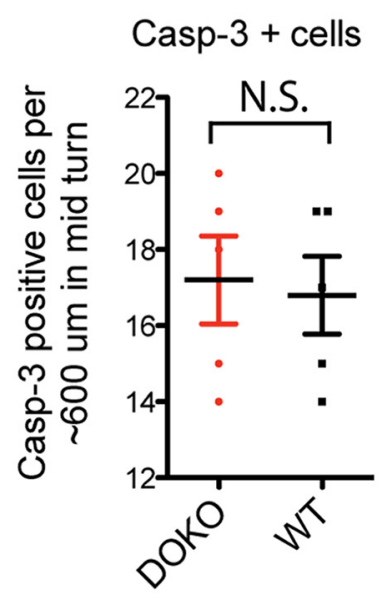

Figure 4. Genetic inhibition of RIPK3-mediated necroptosis and Caspase-8-mediated apoptosis does not affect normal hearing in mice. $\boldsymbol{A}-\boldsymbol{D}$, Auditory brainstem response thresholds of Casp8/Ripk3 DOK0 and WT mice at 8 weeks $(\boldsymbol{A}), 11$ weeks $(\boldsymbol{B}), 14$ weeks $(\boldsymbol{C}$, and 20 weeks $(\boldsymbol{D})$ of age were not significantly different. $\boldsymbol{E}$, Casp-3 staining of the mid-turn of the cochlea in Casp8/Ripk3 DOKO and WT mice at P3 and P8. Cell counts of Casp-3-positive cells indicated no significant difference between Casp8/Ripk3 DOKO and WT mice (two-tailed $t$ test, $p=0.8 ; \boldsymbol{F}$ ). Number of animals (n) per group: WT ( 4 females, 4 males; 8 weeks, $n=8 ; 11$ weeks, $n=7 ; 14$ weeks, $n=6 ; 20$ weeks, $n=6$ ); and Ripk3/Casp-8 DOKO ( 4 females, 4 males; 8 weeks, $n=8 ; 11$ weeks, $n=6 ; 14$ weeks, $n=6 ; 20$ weeks, $n=5$ ). See Table 4-1 available at https://doi.org/10.1523/JNEUROSCI.1384-18.2019.t4-1.

unexposed control mice; Fig. 7A,C). IHCs in Ripk3 KO and Casp8/Ripk3 DOKO mice and mice treated with Nec-1 maintained most IHCs, with minor (10-20\%) losses reported at basal regions compared with untreated controls (Fig. $7 A, C)$. Outer hair cell $(\mathrm{OHC})$ numbers were much more affected by kanamycin exposure: in WT mice exposed to kanamycin, virtually all OHCs were lost (Fig. 7A,B). Ripk3 KO mice showed improved hair cell survival, and the OHCs of Casp8/Ripk3 DOKO mice were most protected (Fig. $7 A, B$ ). Nec-1s-treated mice showed some protection but did not reach the level of Ripk3 $\mathrm{KO}$ mice (Fig. $7 A, B$ ).

In the cisplatin-treated group, inner hair cells were not affected at all, in all mouse genotypes (no quantification shown), while OHCs were affected in a genotype-dependent manner (Fig. $7 D, E$ ). In WT mice exposed to cisplatin, OHC numbers were reduced by $\sim 30 \%$, $50 \%$, and $70 \%$ (apex, mid, and base turns) compared with those of 
A

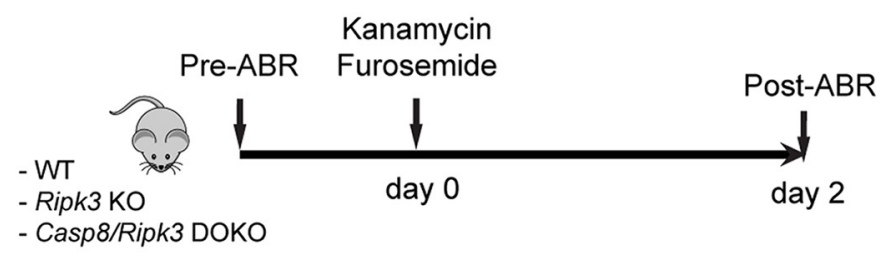

\section{B}
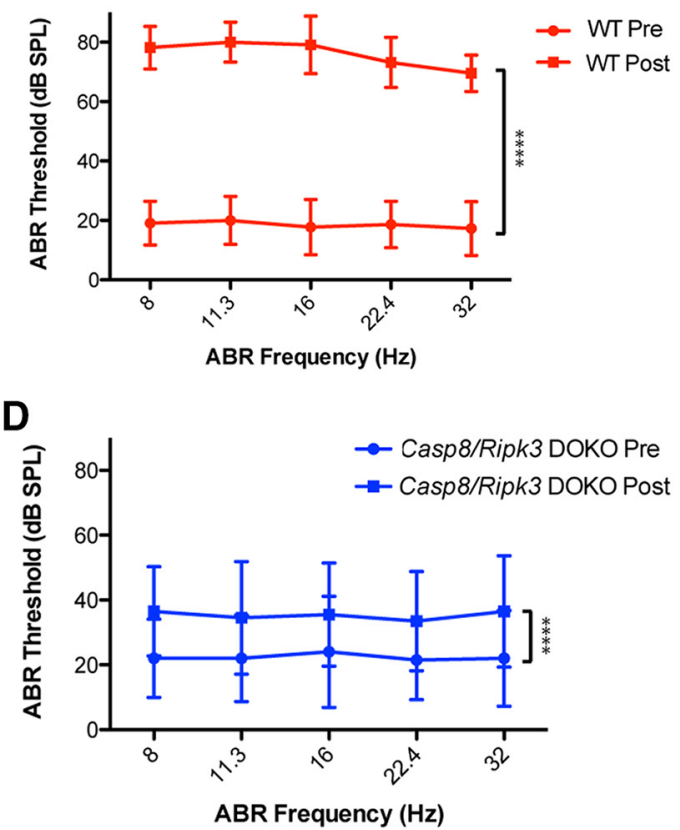

C

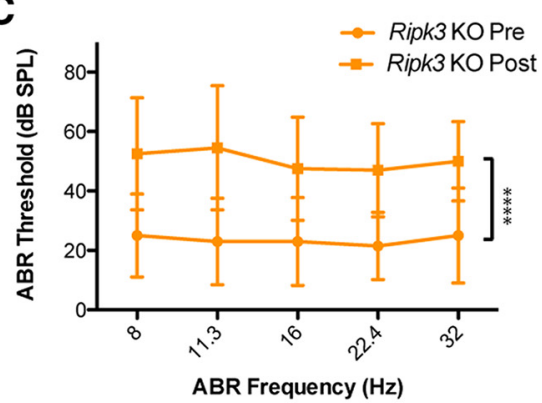

E

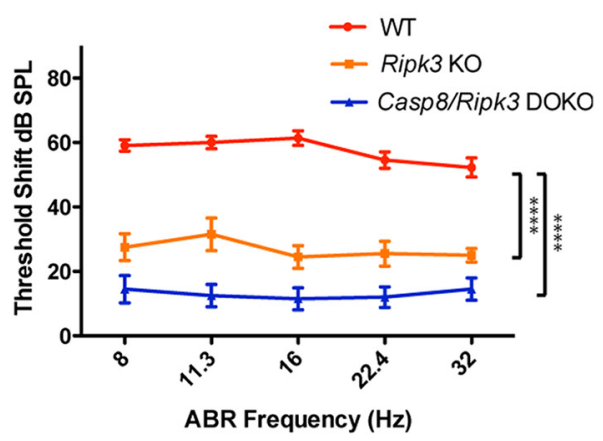

$\mathbf{F}$
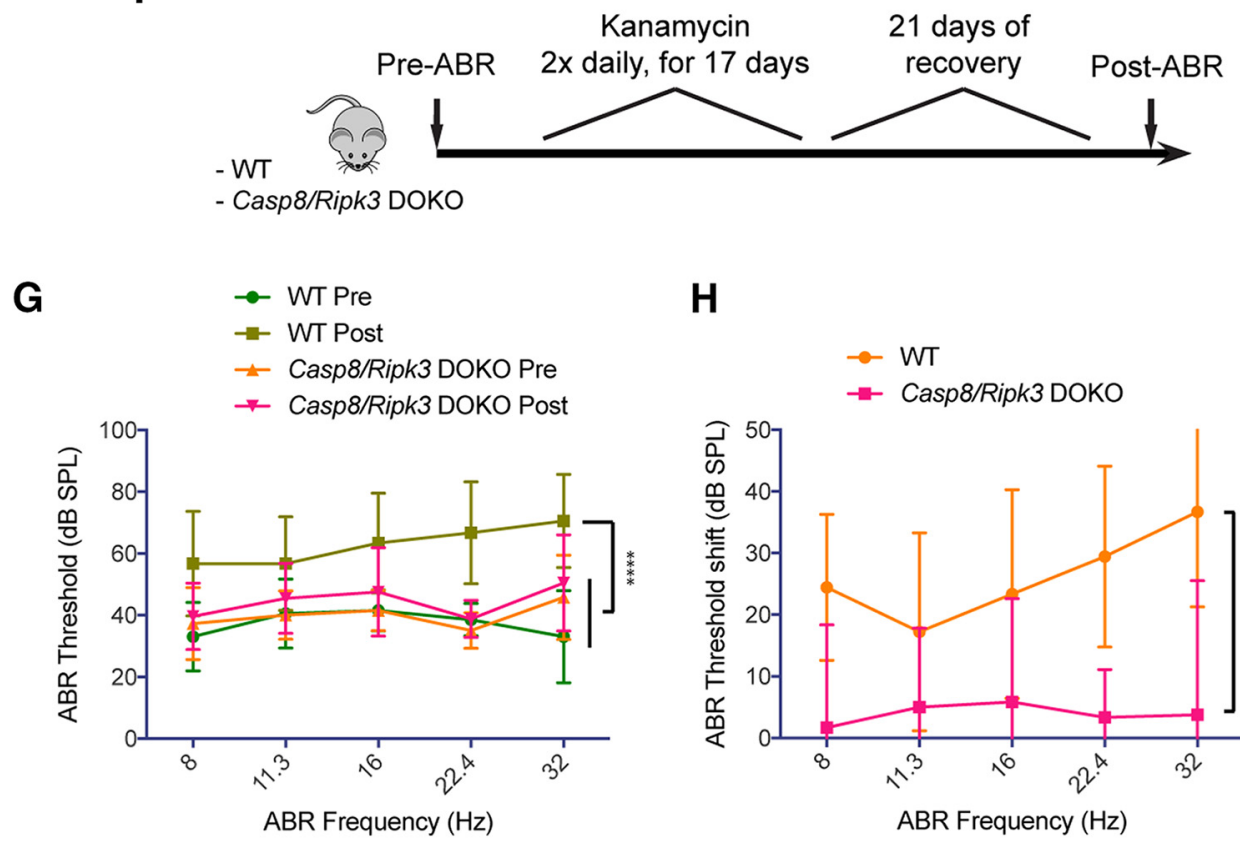

H

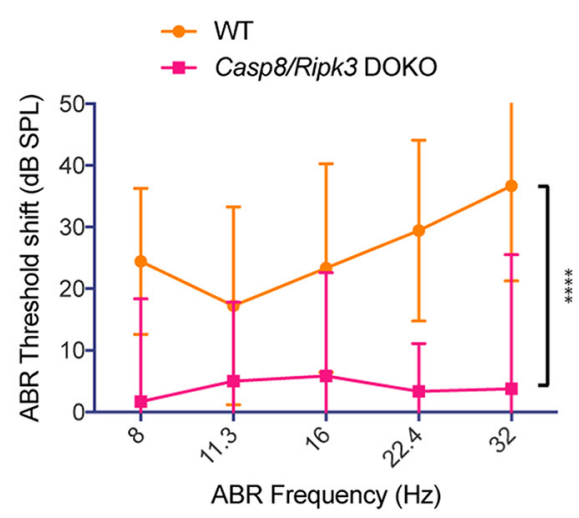

Figure 5. Genetic inhibition of RIPK3-mediated necroptosis and Caspase-8-mediated apoptosis alleviates kanamycin ototoxicity in vivo. A, Schematic illustration of the kanamycin/furosemide combination ototoxicity paradigm in mutant mice. $B$, Auditory thresholds increased $\sim 50-60 \mathrm{~dB}$ compared with pre-exposure in WT mice. $C$, Auditory thresholds increased $\sim 30 \mathrm{~dB}$ compared with pre-exposure in Ripk3 K0 mice. D, Auditory thresholds increased $\sim 15-20 \mathrm{~dB}$ compared with pre-exposure in Casp8/Ripk3 D0K0 mice. $\boldsymbol{E}$, Degree of threshold shift at each frequency for each genotype. $F$, Schematic illustration of the loop diuretic-free kanamycin ototoxicity paradigm. Auditory thresholds increased significantly after kanamycin exposure in WT mice, but not in Casp8/Ripk3 DOKO mice. $\boldsymbol{G}, \boldsymbol{H}$, Plots of absolute ABR thresholds $(\boldsymbol{G})$; and plots of the ABR threshold difference (shift) between pre-ABR and post-ABRs $(\boldsymbol{H})$. Error bars indicate the SD. Statistical significance: ${ }^{* * * *} p<0.00001$. Number of animals $(n)$ per group: WT ( $n=11,7$ females, 4 males); Ripk3 KO ( $n=10,5$ females, 5 males); and Casp $8 /$ Ripk 3 DOKO ( $n=10,7$ females, 3 males). Number of animals $(n)$ in the furosemide-free kanamycin protocol:WT ( $n=10,5$ females, 5 males); and Casp8/Ripk3 DOKO ( $n=13,8$ females, 5 males). See Table 5-1 availableathttps://doi.org/10.1523/JNEUROSCl.1384-18.2019.55-1. 
A
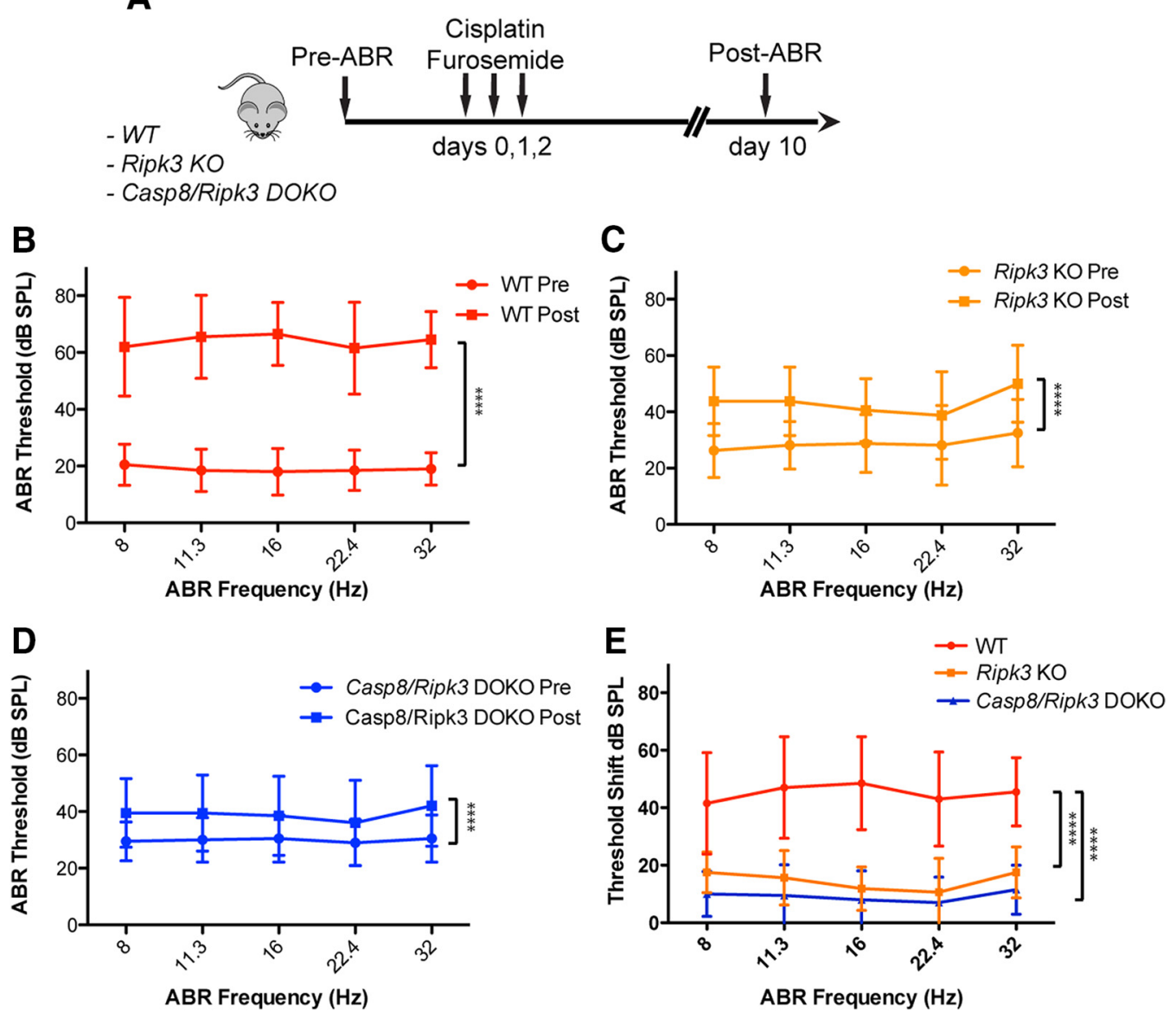

Figure 6. Genetic inhibition of RIPK3-mediated necroptosis and Caspase-8-mediated apoptosis alleviates cisplatin ototoxicity in vivo. $\boldsymbol{A}$, Schematic illustration of the cisplatin/furosemide combination ototoxicity paradigm in mutant mice. $B$, Auditory thresholds increased $\sim 40-50 \mathrm{~dB}$ compared with pre-exposure in WT mice. $C$, Auditory thresholds increased $\sim 15-20 \mathrm{~dB}$ compared with pre-exposure in Ripk3 KO mice. D, Auditory thresholds increased $\sim 10 \mathrm{~dB}$ compared with pre-exposure in Casp8/Ripk3 D0K0 mice. $\boldsymbol{E}$, Degree of threshold shift at each frequency for each genotype. Error bars indicate the SD. Statistical significance: ${ }^{* * *} p<0.00001$. Number of animals ( $n$ ) per group: WT ( $\left.n=10\right)$; Ripk3 K0 ( $n=8,5$ females, 3 males); and Casp8/Ripk3 D0K0 ( $n=$ 10, 7 females, 3 males). See Table 6-1 available at https://doi.org/10.1523/JNEUROSCI.1384-18.2019.t6-1.

untreated controls (Fig. 7D,E). Ripk3 KO mice showed improved hair cell survival, retaining most hair cells at apical and mid turns, but losing $\sim 30 \%$ at the base (Fig. $7 D, E$ ). OHC counts in Casp8/ Ripk3 DOKO mice were similar to the Ripk3 $\mathrm{KO}$ at the apex and mid turns, but were better at the base (Fig. $7 D, E$ ). Nec-1s-treated mice showed some protection compared with WT mice but did not reach the level of Ripk3 KO mice (Fig. 7D,E).

The hair cell protection in Casp8/Ripk3 DOKO mice was also evident in the furosemide-free kanamycin ototoxicity protocol: WT mice experienced a significantly higher degree of OHC loss in the mid and basal turns compared with Casp8/Ripk3 DOKO mice (Fig. $7 F, G$ ). Inner hair cells in both WT and Casp8/Ripk3 DOKO mice were not affected (Fig. $7 F, H$ ).

We conclude that the otoprotective effect of inhibiting RIPK3-mediated necroptosis and Caspase-8-mediated apoptosis correlates with improved hair cell survival.

\section{Discussion}

Necroptosis is executed by RIPK1 and RIPK3 when apoptosismediating caspases are inhibited (Yuan et al., 2016). Due to this compensatory interplay between the cell death pathways, necroptosis and apoptosis are best studied in mutual context. We achieved this by studying the ototoxic response of mouse models in which RIPK3-mediated necroptosis, and/or Caspase-8mediated apoptosis is disrupted. In addition, we tested the ex vivo and in vivo efficiency of the small-molecule inhibitor of RIPK1 $\mathrm{Nec}-1 \mathrm{~s}$.

Historically, both ex vivo and in vivo studies have provided important insights into the mechanisms underlying hair cell death pathways (Wu et al., 2001; Wang et al., 2004; Rybak and Ramkumar, 2007; Rybak, 2007; Guthrie, 2008; Warchol, 2010; Ding et al., 2011; Schacht et al., 2012; Francis et al., 2013; Nicholas et al., 2017). The conclusions, however, differ significantly between the ex vivo and in vivo context, and thus have created confusion in the ototoxicity field. In general, apoptotic cell death was more frequently implicated in ex vivo studies on neonatal organ cultures, while a mix of apoptotic, necrotic, and caspaseindependent cell death was implicated in in vivo studies performed in mature mice (Forge and Schacht, 2000; Cheng et al., 2005; Jiang et al., 2006; Rybak et al., 2006; Rybak and Ramkumar, 2007; Huth et al., 2011; Schacht et al., 2012; Sheth et al., 2017). This is in good agreement with our present study: in our ex vivo experiments, addition of the necroptosis inhibitor Nec-1s had no effect on hair cell survival. Furthermore, the pan-caspase inhibitor zVAD-FMK provided virtually complete protection against both kanamycin- and cisplatin-induced hair cell deaths. If hair cells ex vivo were capable of necroptosis, a subset would have undergone necroptotic cell death despite the inhibition of caspases by zVAD-FMK, since the inhibition of caspases triggers 
A

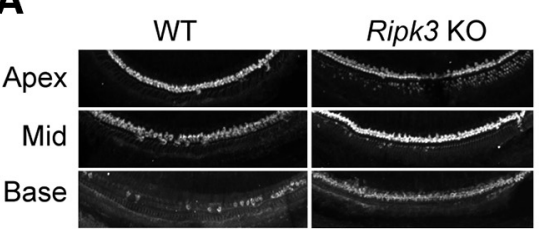

Casp8/Ripk3

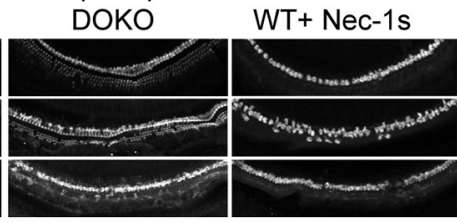

\section{B}

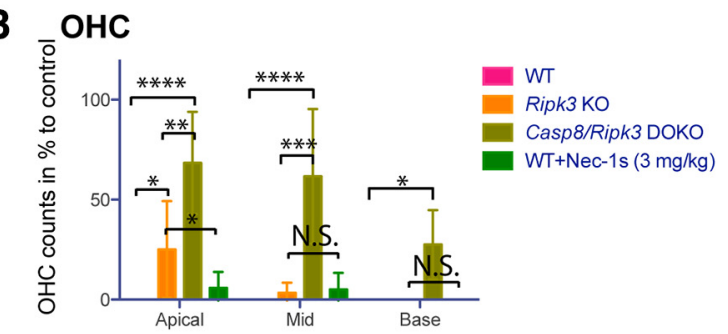

C
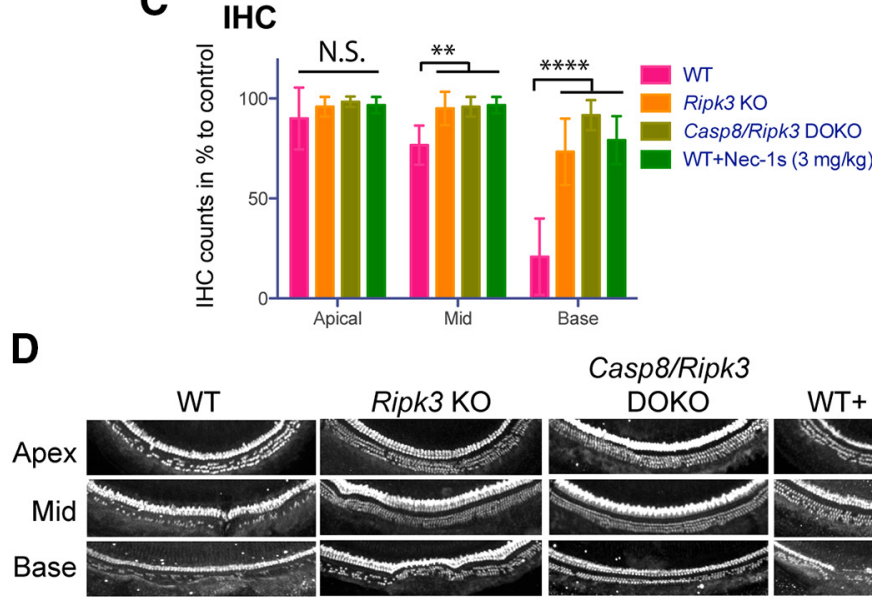

Casp8/Ripk3
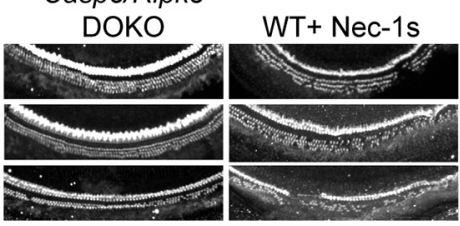

E

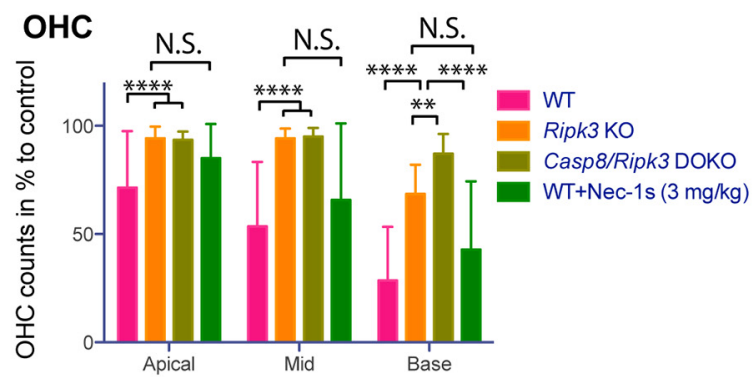

$\mathbf{F}$

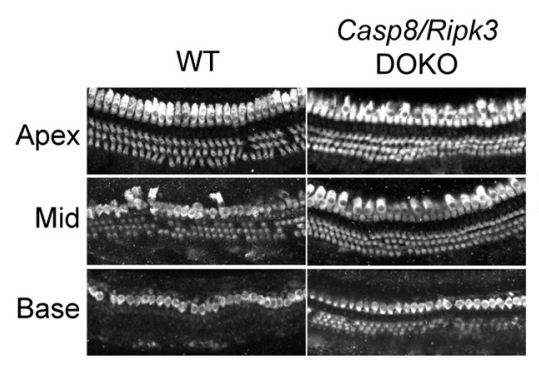

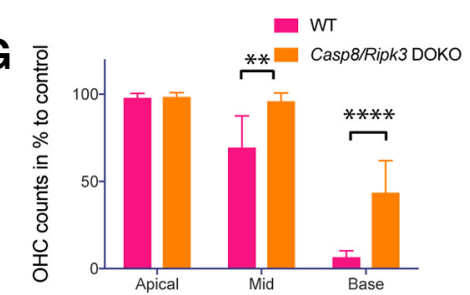

$\mathrm{H}$

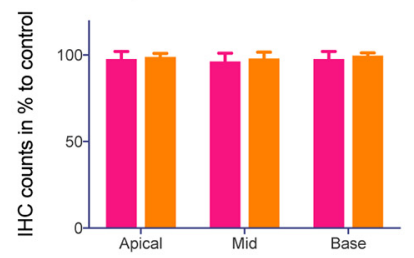

Figure 7. The otoprotective effect of inhibiting RIPK3-mediated necroptosis and Caspase-8 mediated apoptosis correlates with improved hair cell survival. A, MY07A immunofluorescence-based hair cell counts after treatment with kanamycin stratified by genotype showing a protective effect in Ripk3 KO, Casp8/Ripk3 DOKO and WT treated with Nec-1s. B, OHC counts after treatment with kanamycin stratified by genotype and treatment with Nec-1s. C, IHC counts after treatment with kanamycin stratified by genotype and treatment with Nec-1s. D, Cell counts of cochleae after treatment with cisplatin stratified by genotype showing a

necroptosis (Zheng et al., 2014; Yuan et al., 2016). It is thus likely that in the exvivo context, most, if not all hair cell death can be attributed to caspase-mediated apoptosis, while in vivo, both necroptosis and apoptosis contribute to kanamycin and cisplatin ototoxicities. Various mechanisms might contribute to the differential involvement of necroptosis in neonatal explants compared with in vivo studies in adult mice: for instance, the expression of necroptosis meditators such as RIPK3 could be restricted to the mature cochlea. We attempted to determine RIPK3 protein expression in the cochlea at different ages, but none of the tested antibodies (listed in Materials and Methods) showed specific immunoreactivities (staining persisted in Ripk3 KO mice; data not shown). We were therefore unable to resolve this matter conclusively. In addition to potential age-dependent expression of cell death mediators, the denervation of hair cells and the absence of endolymph and strial environment in the ex vivo context, might contribute to the differences between in vivo and ex vivo results. Last, it is also possible that the difference is caused by the inclusion of loop diuretics in most of the in vivo studies in this report. We addressed this mismatch by confirming that Casp8/Ripk3 DOKO mice maintained protection in a kanamycin ototoxicity protocol without loop diuretics, suggesting that the difference between $e x$ vivo and in vivo results were not caused by loop diuretics.

With the aforementioned lack of cellular expression data on RIPK3, our study does not allow any definitive conclusions to be drawn with respect to the primary target cell type of necroptosis in the inner ear. In our study, hearing rescue correlates

\footnotetext{
$\leftarrow$

protective effect in Ripk3 KO, Casp8/Ripk3 DOKO and WT treated with Nec-1s. $\boldsymbol{E}, \mathrm{OHC}$ counts after treatment with cisplatin stratified by genotype and treatment with Nec-1s. $\boldsymbol{F}$, Cochlear hair cell counts of mice exposed to the furosemidefree kanamycin protocol. F, G, WT mice suffered a significantly higher degree of $\mathrm{OHCl}$ loss in the mid and basal turns compared to Casp8/Ripk3 DOKO mice. IHCs in both WT and Casp8/Ripk3 DOKO were unaffected $(\boldsymbol{H})$. Error bars indicate the SD. Statistical significance: ${ }^{* * *} p<0.00001,{ }^{* * *} p<0.0001,{ }^{* *} p<$ $0.001,{ }^{*} p<0.05$. Number of animals $(n)$ per group, only 1 ear per group was analyzed: WT, cisplatin treated $(n=7)$, Ripk3 $K O$, cisplatin treated $(n=7)$, Casp8/Ripk3 DOKO, cisplatin treated $(n=7)$, WT, cisplatin-treated + Nec-1s $(3 \mathrm{mg} / \mathrm{kg})$ treated ( $n=7)$, WT, kanamycin treated $(n=6)$, Ripk3 KO, kanamycin treated ( $n=7)$, Casp8/Ripk3 DOKO, kanamycin treated $(n=6)$, WT, kanamycin-treated + Nec- $1 \mathrm{~s}(3 \mathrm{mg} / \mathrm{kg})$ treated $(n=6)$. Furosemide-free kanamycin protocol: WT $(n=6)$, Casp8/Ripk3 DOKO $(n=6)$. See Table 7-1 available at https://doi.org/10.1523/JNEUROSCI.1384-18.2019.t7-1.
} 
with improved hair cell survival, which is consistent with the hypothesis that hair cells are the mediators of necroptosismediated ototoxicity and otoprotection. However, the benefit of necroptosis and apoptosis inhibition for hair cell survival might be secondary, possibly by the protection of other cell types such as strial cells. The identity of the cell types sensitive to necroptosis in the inner ear remains unresolved and needs to be addressed in future studies using cell type-specific genetic manipulations.

It is noteworthy that a furosemide-free cisplatin ototoxicity protocol caused nearly complete mortality in Casp8/Ripk3 DOKO mice, despite the survival of WT control mice. We believe that this result provides an argument for the use of loop diuretic-aided ototoxicity protocols, especially for sensitive genetic mouse models and for studying cisplatin ototoxicity, which is known to suffer from a narrow effective dose window (Hill et al., 2008; More et al., 2010; Poirrier et al., 2010). It is without question, however, that the inclusion of additional variables such as loop diuretics complicates the interpretation of the findings, necessitating diligent controls.

To date, only a few other studies have explored the role of necroptosis in any type of ototoxicity. Zheng et al. (2014) reported that Nec-1 alleviates noise-induced hearing loss in the mouse. Nec-1 was also reported to protect spiral ganglion neurons and improve ABR thresholds in rats exposed to ouabain (Wang et al., 2014). Finally, Park et al. (2012) reported that NecroX, yet another necroptosis inhibitor, prevented gentamicin-induced hair cell loss in neonatal mouse organ of Corti explants. The latter report contradicts our results, which did not observe a protective effect of Nec-1s ex vivo. The inconsistency might be caused by differences in kinase inhibitor profiles between NecroX and Nec-1s, including off-target inhibition of related kinases.

Our study also provided new insight into the involvement of apoptosis in drug-induced ototoxicity. Previous studies have provided evidence for an involvement of apoptosis in vivo. In the chick, Matsui et al. (2003) showed that infusion of zVAD-FMK into the inner ear protected from streptomycin-induced hair cell death. Similarly, the infusion of z-DEVD-FMK provided protection from cisplatin-induced ototoxicity in Guinea pigs in vivo (Wang et al., 2004). In contrast, Jiang et al. (2006) reported that in mice exposed to kanamycin, hair cell nuclei exhibited both apoptotic- and necrotic-like appearances, but lacked molecular hallmarks of classic apoptotic pathways (e.g., caspases, cytochrome C, TUNEL). Our use of Casp 8 KO mice (on a Ripk3 KO background) provides for the first time genetic evidence that Caspase-8-mediated apoptosis, also known as death receptormediated or extrinsic apoptosis, is involved in cisplatin- and kanamycin-mediated ototoxicity. The involvement of another arm of apoptosis, mitochondrial (intrinsic) apoptosis, was not tested in this study, but previous studies using Caspase-9 inhibitors indicate that intrinsic apoptotic pathways are implicated in various ototoxicities (Wang et al., 2003).

In contrast to apoptosis characterized by its traceless removal of dead cells, necroptosis, due to the release of intracellular components acting as damage-associated molecular patterns in the extracellular space, creates an inflammatory response, which is often beneficial for resolving the insult (Kaczmarek et al., 2013). A necroptotic response in the inner ear thus would only make sense if the inner ear was not "immune privileged," as historically assumed, but was capable of mounting a significant immunological response. In fact, more recent studies suggest that the resolution of ototoxic insults is aided by immune cells infiltrating into the inner ear (Kaur et al., 2015a,b, 2018; Francis and Cunning- ham, 2017; Mizushima et al., 2017; Wood and Zuo, 2017; Barald et al., 2018; Liu et al., 2018). Such immune activity, beneficial under normal circumstances, might become counterproductive when ototoxins overwhelm the system, creating a massive, detrimental immune response. The present study provides insight into the basic mechanisms underlying drug-induced hearing loss and, importantly, opens up avenues for pharmacological intervention toward clinical therapy. The potential clinical uses of the small-molecule inhibitor RIPK1 Nec-1s, which can pass the blood-brain barrier, are already being investigated for neurodegenerative diseases (Zhang et al., 2017), and clinical trials are underway for other necroptosis inhibitors (Weisel et al., 2017). It seems prudent that this class of medication may be translated into clinical studies to assess its otoprotective capabilities.

\section{References}

Alam SA, Ikeda K, Oshima T, Suzuki M, Kawase T, Kikuchi T, Takasaka T (2000) Cisplatin-induced apoptotic cell death in Mongolian gerbil cochlea. Hear Res 141:28-38.

Barald KF, Shen YC, Bianchi LM (2018) Chemokines and cytokines on the neuroimmunoaxis: inner ear neurotrophic cytokines in development and disease. Prospects for repair? Exp Neurol 301:92-99.

Benkafadar N, Menardo J, Bourien J, Nouvian R, François F, Decaudin D, Maiorano D, Puel JL, Wang J (2017) Reversible p53 inhibition prevents cisplatin ototoxicity without blocking chemotherapeutic efficacy. EMBO Mol Med 9:7-26.

Boatright KM, Salvesen GS (2003) Mechanisms of caspase activation. Curr Opin Cell Biol 15:725-731.

Burdett S, Pignon JP, Tierney J, Tribodet H, Stewart L, Le Pechoux C, Aupérin A, Le Chevalier T, Stephens RJ, Arriagada R, Higgins JP, Johnson DH, Van Meerbeeck J, Parmar MK, Souhami RL, Bergman B, Douillard JY, Dunant A, Endo C, Girling D, et al. (2015) Adjuvant chemotherapy for resected early-stage non-small cell lung cancer. Cochrane Database Syst Rev. Advance online publication. Retrieved March 2, 2015. doi: 10.1002/ 14651858.CD011430.

Chen M, Wang J (2002) Initiator caspases in apoptosis signaling pathways. Apoptosis 7:313-319.

Cheng AG, Cunningham LL, Rubel EW (2003) Hair cell death in the avian basilar papilla: characterization of the in vitro model and caspase activation. J Assoc Res Otolaryngol 4:91-105.

Cheng AG, Cunningham LL, Rubel EW (2005) Mechanisms of hair cell death and protection. Curr Opin Otolaryngol Head Neck Surg 13:343348.

Clerici WJ, Hensley K, DiMartino DL, Butterfield DA (1996) Direct detection of ototoxicant-induced reactive oxygen species generation in cochlear explants. Hear Res 98:116-124.

Coffin AB, Rubel EW, Raible DW (2013) Bax, Bcl2, and p53 differentially regulate neomycin- and gentamicin-induced hair cell death in the zebrafish lateral line. J Assoc Res Otolaryngol 14:645-659.

Cunningham LL, Matsui JI, Warchol ME, Rubel EW (2004) Overexpression of bcl-2 prevents neomycin-induced hair cell death and caspase- 9 activation in the adult mouse utricle in vitro. J Neurobiol 60:89-100.

Degterev A, Huang Z, Boyce M, Li Y, Jagtap P, Mizushima N, Cuny GD, Mitchison TJ, Moskowitz MA, Yuan J (2005) Chemical inhibitor of nonapoptotic cell death with therapeutic potential for ischemic brain injury. Nat Chem Biol 1:112-119.

Dehne N, Lautermann J, ten Cate WJ, Rauen U, de Groot H (2000) In vitro effects of hydrogen peroxide on the cochlear neurosensory epithelium of the guinea pig. Hear Res 143:162-170.

Ding D, He J, Allman BL, Yu D, Jiang H, Seigel GM, Salvi RJ (2011) Cisplatin ototoxicity in rat cochlear organotypic cultures. Hear Res 282:196203.

Duprez L, Takahashi N, Van Hauwermeiren F, Vandendriessche B, Goossens V, Vanden Berghe T, Declercq W, Libert C, Cauwels A, Vandenabeele P (2011) RIP kinase-dependent necrosis drives lethal systemic inflammatory response syndrome. Immunity 35:908-918.

Einhorn LH (2002) Curing metastatic testicular cancer. Proc Natl Acad Sci U S A 99:4592-4595.

Forge A, Li L (2000) Apoptotic death of hair cells in mammalian vestibular sensory epithelia. Hear Res 139:97-115. 
Forge A, Schacht J (2000) Aminoglycoside antibiotics. Audiol Neurootol 5:3-22.

Francis SP, Cunningham LL (2017) Non-autonomous cellular responses to ototoxic drug-induced stress and death. Front Cell Neurosci 11:252.

Francis SP, Katz J, Fanning KD, Harris KA, Nicholas BD, Lacy M, Pagana J, Agris PF, Shin JB (2013) A novel role of cytosolic protein synthesis inhibition in aminoglycoside ototoxicity. J Neurosci 33:3079-3093.

Guthrie OW (2008) Aminoglycoside induced ototoxicity. Toxicology 249:91-96.

He S, Wang L, Miao L, Wang T, Du F, Zhao L, Wang X (2009) Receptor interacting protein kinase-3 determines cellular necrotic response to TNF- $\alpha$. Cell 137:1100-1111.

Hill GW, Morest DK, Parham K (2008) Cisplatin-induced ototoxicity: effect of intratympanic dexamethasone injections. Otol Neurotol 29:1005-1011.

Hinojosa R (1977) A note on development of corti's organ. Acta Otolaryngol 84:238-251.

Hirose K, Sato E (2011) Comparative analysis of combination kanamycinfurosemide versus kanamycin alone in the mouse cochlea. Hear Res 272:108-116.

Hirose K, Hockenbery DM, Rubel EW (1997) Reactive oxygen species in chick hair cells after gentamicin exposure in vitro. Hear Res 104:1-14.

Huth ME, Ricci AJ, Cheng AG (2011) Mechanisms of aminoglycoside ototoxicity and targets of hair cell protection. Int J Otolaryngol 2011:937861.

Jiang H, Sha SH, Forge A, Schacht J (2006) Caspase-independent pathways of hair cell death induced by kanamycin in vivo. Cell Death Differ 13:2030.

Kaczmarek A, Vandenabeele P, Krysko DV (2013) Necroptosis: the release of damage-associated molecular patterns and its physiological relevance. Immunity 38:209-223.

Kaiser WJ, Upton JW, Long AB, Livingston-Rosanoff D, Daley-Bauer LP, Hakem R, Caspary T, Mocarski ES (2011) RIP3 mediates the embryonic lethality of caspase-8-deficient mice. Nature 471:368-372.

Kamiya K, Takahashi K, Kitamura K, Momoi T, Yoshikawa Y (2001) Mitosis and apoptosis in postnatal auditory system of the $\mathrm{C} 3 \mathrm{H} / \mathrm{He}$ strain. Brain Res 901:296-302.

Karasawa T, Steyger PS (2015) An integrated view of cisplatin-induced nephrotoxicity and ototoxicity. Toxicol Lett 237:219-227.

Kaur T, Hirose K, Rubel EW, Warchol ME (2015a) Macrophage recruitment and epithelial repair following hair cell injury in the mouse utricle. Front Cell Neurosci 9:150.

Kaur T, Zamani D, Tong L, Rubel EW, Ohlemiller KK, Hirose K, Warchol ME (2015b) Fractalkine signaling regulates macrophage recruitment into the cochlea and promotes the survival of spiral ganglion neurons after selective hair cell lesion. J Neurosci 35:15050-15061.

Kaur T, Ohlemiller KK, Warchol ME (2018) Genetic disruption of fractalkine signaling leads to enhanced loss of cochlear afferents following ototoxic or acoustic injury. J Comp Neurol 526:824-835.

Knipper M, Gestwa L, Ten Cate WJ, Lautermann J, Brugger H, Maier H, Zimmermann U, Rohbock K, Köpschall I, Wiechers B, Zenner HP (1999) Distinct thyroid hormone-dependent expression of trkB and p75(NGFR) in nonneuronal cells during the critical TH-dependent period of the cochlea. J Neurobiol 38:338-356.

Kopke RD, Liu W, Gabaizadeh R, Jacono A, Feghali J, Spray D, Garcia P, Steinman H, Malgrange B, Ruben RJ, Rybak L, Van de Water TR (1997) Use of organotypic cultures of Corti's organ to study the protective effects of antioxidant molecules on cisplatin-induced damage of auditory hair cells. Am J Otol 18:559-571.

Lautermann J, McLaren J, Schacht J (1995) Glutathione protection against gentamicin ototoxicity depends on nutritional status. Hear Res 86:15-24.

Li J, McQuade T, Siemer AB, Napetschnig J, Moriwaki K, Hsiao YS, Damko E, Moquin D, Walz T, McDermott A, Chan FK, Wu H (2012) The RIP1/ RIP3 necrosome forms a functional amyloid signaling complex required for programmed necrosis. Cell 150:339-350.

Li Y, Ding D, Jiang H, Fu Y, Salvi R (2011) Co-administration of cisplatin and furosemide causes rapid and massive loss of cochlear hair cells in mice. Neurotox Res 20:307-319.

Liang F, Schulte BA, Qu C, Hu W, Shen Z (2005) Inhibition of the calciumand voltage-dependent big conductance potassium channel ameliorates cisplatin-induced apoptosis in spiral ligament fibrocytes of the cochlea. Neuroscience 135:263-271.

Linkermann A, Green DR (2014) Necroptosis. N Engl J Med 370:455-465.
Liu W, Molnar M, Garnham C, Benav H, Rask-Andersen H (2018) Macrophages in the human cochlea: saviors or predators-A study using superresolution immunohistochemistry. Front Immunol 9:223.

Marcotti W, van Netten SM, Kros CJ (2005) The aminoglycoside antibiotic dihydrostreptomycin rapidly enters mouse outer hair cells through the mechano-electrical transducer channels. J Physiol 567:505-521.

Matsui JI, Haque A, Huss D, Messana EP, Alosi JA, Roberson DW, Cotanche DA, Dickman JD, Warchol ME (2003) Caspase inhibitors promote vestibular hair cell survival and function after aminoglycoside treatment in vivo. J Neurosci 23:6111-6122.

Mizushima Y, Fujimoto C, Kashio A, Kondo K, Yamasoba T (2017) Macrophage recruitment, but not interleukin 1 beta activation, enhances noiseinduced hearing damage. Biochem Biophys Res Commun 493:894-900.

More SS, Akil O, Ianculescu AG, Geier EG, Lustig LR, Giacomini KM (2010) Role of the copper transporter, CTR1, in platinum-induced ototoxicity. J Neurosci 30:9500-9509.

Murakami Y, Matsumoto H, Roh M, Giani A, Kataoka K, Morizane Y, Kayama M, Thanos A, Nakatake S, Notomi S, Hisatomi T, Ikeda Y, Ishibashi T, Connor KM, Miller JW, Vavvas DG (2014) Programmed necrosis, not apoptosis, is a key mediator of cell loss and DAMP-mediated inflammation in dsRNA-induced retinal degeneration. Cell Death Differ 21:270-277.

Newton K, Sun X, Dixit VM (2004) Kinase RIP3 is dispensable for normal NF-kappa bs, signaling by the B-cell and T-cell receptors, tumor necrosis factor receptor 1, and toll-like receptors 2 and 4. Mol Cell Biol 24:14641469.

Nicholas BD, Francis S, Wagner EL, Zhang S, Shin JB (2017) Protein synthesis inhibition and activation of the c-jun $\mathrm{N}$-terminal kinase are potential contributors to cisplatin ototoxicity. Front Cell Neurosci 11:303.

Okuda T, Sugahara K, Takemoto T, Shimogori H, Yamashita H (2005) Inhibition of caspases alleviates gentamicin-induced cochlear damage in guinea pigs. Auris Nasus Larynx 32:33-37.

Park MK, Lee BD, Chae SW, Chi J, Kwon SK, Song JJ (2012) Protective effect of NecroX, a novel necroptosis inhibitor, on gentamicin-induced ototoxicity. Int J Pediatr Otorhinolaryngol 76:1265-1269.

Poirrier AL, Van den Ackerveken P, Kim TS, Vandenbosch R, Nguyen L, Lefebvre PP, Malgrange B (2010) Ototoxic drugs: difference in sensitivity between mice and guinea pigs. Toxicol Lett 193:41-49.

Priuska EM, Schacht J (1995) Formation of free radicals by gentamicin and iron and evidence for an iron/gentamicin complex. Biochem Pharmacol 50:1749-1752.

Ramachandran A, McGill MR, Xie Y, Ni HM, Ding WX, Jaeschke H (2013) Receptor interacting protein kinase 3 is a critical early mediator of acetaminophen-induced hepatocyte necrosis in mice. Hepatology 58 : 2099-2108.

Richardson GP, Forge A, Kros CJ, Fleming J, Brown SD, Steel KP (1997) Myosin VIIA is required for aminoglycoside accumulation in cochlear hair cells. J Neurosci 17:9506-9519.

Roy S, Ryals MM, Van den Bruele AB, Fitzgerald TS, Cunningham LL (2013) Sound preconditioning therapy inhibits ototoxic hearing loss in mice. J Clin Invest 123:4945-4949.

Rybak LP (2007) Mechanisms of cisplatin ototoxicity and progress in otoprotection. Curr Opin Otolaryngol Head Neck Surg 15:364-369.

Rybak LP, Ramkumar V (2007) Ototoxicity. Kidney Int 72:931-935.

Rybak LP, Talaska AE, Schacht J (2006) Drug-induced hearing loss. In: Auditory trauma, protection, and repair (Schacht J, Popper AN, Fay RR, eds), pp 219-256. New York: Springer.

Salmena L, Lemmers B, Hakem A, Matysiak-Zablocki E, Murakami K, Au PY, Berry DM, Tamblyn L, Shehabeldin A, Migon E, Wakeham A, Bouchard D, Yeh WC, McGlade JC, Ohashi PS, Hakem R (2003) Essential role for caspase 8 in T-cell homeostasis and T-cell-mediated immunity. Genes Dev 17:883-895.

Schacht J, Talaska AE, Rybak LP (2012) Cisplatin and aminoglycoside antibiotics: hearing loss and its prevention. Anat Rec (Hoboken) 295:18371850.

Sheth S, Mukherjea D, Rybak LP, Ramkumar V (2017) Mechanisms of cisplatin-induced ototoxicity and otoprotection. Front Cell Neurosci 11: 338.

St Germain C, Niknejad N, Ma L, Garbuio K, Hai T, Dimitroulakos J (2010) Cisplatin induces cytotoxicity through the mitogen-activated protein kinase pathways ana activating transcription factor 3. Neoplasia 12:527538. 
Taylor RR, Nevill G, Forge A (2008) Rapid hair cell loss: a mouse model for cochlear lesions. J Assoc Res Otolaryngol 9:44-64.

Tristão VR, Pessoa EA, Nakamichi R, Reis LA, Batista MC, Durão Junior Mde S, Monte JC (2016) Synergistic effect of apoptosis and necroptosis inhibitors in cisplatin-induced nephrotoxicity. Apoptosis 21:51-59.

Wang J, Van De Water TR, Bonny C, de Ribaupierre F, Puel JL, Zine A (2003) A peptide inhibitor of $\mathrm{c}$-jun $\mathrm{N}$-terminal kinase protects against both aminoglycoside and acoustic trauma-induced auditory hair cell death and hearing loss. J Neurosci 23:8596-8607.

Wang J, Ladrech S, Pujol R, Brabet P, Van De Water TR, Puel JL (2004) Caspase inhibitors, but not c-jun NH2-terminal kinase inhibitor treatment, prevent cisplatin-induced hearing loss. Cancer Res 64:9217-9224.

Wang Q, Zhou T, Liu Z, Ren J, Phan N, Gupta K, Stewart DM, Morgan S, Assa C, Kent KC, Liu B (2017) Inhibition of receptor-interacting protein kinase 1 with necrostatin-1s ameliorates disease progression in elastaseinduced mouse abdominal aortic aneurysm model. Sci Rep 7:42159.

Wang X, Wang Y, Ding ZJ, Yue B, Zhang PZ, Chen XD, Chen X, Chen J, Chen FQ, Chen Y, Wang RF, Mi WJ, Lin Y, Wang J, Qiu JH (2014) The role of RIP3 mediated necroptosis in ouabain-induced spiral ganglion neurons injuries. Neurosci Lett 578:111-116.

Warchol ME (2010) Cellular mechanisms of aminoglycoside ototoxicity. Curr Opin Otolaryngol Head Neck Surg 18:454-458.
Weinlich R, Oberst A, Beere HM, Green DR (2017) Necroptosis in development, inflammation and disease. Nat Rev Mol Cell Biol 18:127-136.

Weisel K, Scott NE, Tompson DJ, Votta BJ, Madhavan S, Povey K, Wolstenholme A, Simeoni M, Rudo T, Richards-Peterson L, Sahota T, Wang JG, Lich J, Finger J, Verticelli A, Reilly M, Gough PJ, Harris PA, Bertin J, Wang ML (2017) Randomized clinical study of safety, pharmacokinetics, and pharmacodynamics of RIPK1 inhibitor GSK2982772 in healthy volunteers. Pharmacol Res Perspect 5:e00365.

Wood MB, Zuo J (2017) The contribution of immune infiltrates to ototoxicity and cochlear hair cell loss. Front Cell Neurosci 11:106.

Wu WJ, Sha SH, McLaren JD, Kawamoto K, Raphael Y, Schacht J (2001) Aminoglycoside ototoxicity in adult CBA, C57BL and BALB mice and the Sprague-Dawley rat. Hear Res 158:165-178.

Yuan J, Najafov A, Py BF (2016) Roles of caspases in necrotic cell death. Cell 167:1693-1704

Zhang M, Liu W, Ding D, Salvi R (2003) Pifithrin-alpha supresses p53 and protects cochlear and vestibular hair cells from cisplatin-induced apoptosis. Neuroscience 120:191-205.

Zhang S, Tang MB, Luo HY, Shi CH, Xu YM (2017) Necroptosis in neurodegenerative diseases: a potential therapeutic target. Cell Death Dis 8:e2905

Zheng HW, Chen J, Sha SH (2014) Receptor-interacting protein kinases modulate noise-induced sensory hair cell death. Cell Death Dis 5:e1262. 